Original title / titulo original: ¿Qué sabemos de qillqa en Quila Suyu?

Author(s)/ autor(es):

Jan Szeminski

Published originally as/ Publicado originalmente en:

Estudios Latinoamericanos, 30 (2010), pp. 129-186

DOI: https://doi.org/10.36447/Estudios2010.v30.art7

Estudios Latinoamericanos is a journal published by the Polish Society for Latin American Studies (Polskie Towarzystwo Studiów Latynoamerykanistycznych).

The Polish Society for Latin American Studies is scholarly organization established to facilitate research on Latin America and to encourage and promote scientific and cultural cooperation between Poland and Latin America.

Estudios Latinoamericanos, revista publicada por la Sociedad Polaca de Estudios Latinoamericanos (Polskie Towarzystwo Studiów Latynoamerykanistycznych).

Sociedad Polaca de Estudios Latinoamericanos es una asociación científica fundada con el fin de desarrollar investigaciones científicas sobre América Latina y participar en la cooperación científica y cultural entre las sociedades de Polonia y América Latina. 


\title{
¿Qué sabemos de qillqa en Qulla Suyu?
}

\author{
Jan Szemiński
}

\section{Introducción}

Cegún los conquistadores y misioneros del siglo dieciséis, y también según los in$\checkmark$ vestigadores del siglo veinte y veintiuno, los habitantes de los Andes Centrales no conocían la escritura antes de la conquista española. Esta convicción, muy divulgada y aceptada, fue la causa de que los investigadores, con muy pocas excepciones, no investigaran el problema de la escritura en los Andes Centrales. Mucho mejor fue tratado el khipu, ya que la tradición de su uso sobrevivió hasta el siglo veinte. La posibilidad de la existencia de otras formas de anotar y preservar información no fue considerada seriamente, aunque los autores españoles del siglo dieciséis observaron formas de notación cuyos rasgos sugieren la existencia de un sistema pictográfico. Hacia 1575, en el Cuzco, Christoual de Molina anotó lo que sigue en sus Ritos y fábulas de los Incas:

[1r] Y para entender donde tuuieron origen sus ydolatrias porque es assi q[ue] estos no usaron de escritura y tenian en vna casa de el Sol Llamada Poquen Cancha q[ue] es Junto aL Cuzco la uida de cada vno de los yngas y de las tierras q[ue] conquisto pintado por sus figuras en vnas tablas, y q[ue] origen tuuieron, y entre Las dichas pinturas tenian assimismo pintada La fabuLa sig[uien]te [1v] En Lauida de mango capac que fue El primer ynca de donde enpeçaron A jatarse y llamarse Hijos del sol y a tener principio La ydolatria y adoracion Del sol.

Jan Szemiński • Universidad Hebrea de Jerusalén. E-mail: msinqa@mscc.huji.ac.il 
A continuación cito el texto de la fábula sin los añadidos introducidos por Molina y dejo solamente lo que pudo ser una traducción de "la fabula siguiente" según el análisis que publiqué en 2005 (Szemiński 2005):

$y$ dizen que eneL peresçieron todas Las Jentes y todas Las cosas Criadas De tal manera que Las Aguas Suuieron Sobre Los mas altos çerros queenel mundo Auian de suerte que no quedo cossa biua Eçepto Vn Hombre y Vna muger que quedaron En Vna caja de Vn atambor y que aL tiempo que Se rrecojiero[n] Las Aguas El uiento Hecho a estos en tia Huanaco y que el Haçedor de todas Las cossas Les mando que alli quedasen por mitimas y que alli en tia huanaco El haçedor enpeço hazer Las Jentes y naçiones que en esta tierra ay Y Haziendo de barro cada nacion pintandoles Los trajes y Vestidos que cada Vno Auia de traer y tener y Los que auian de traer cauellos concauello y los que cortado cortado El cauello y q[ue] Concluydo A cada nacion dio La lengua que auia de hablar $y$ Los cantos que auian de cantar $y$ Las simientes $y$ Comidas que auian de sembrar $y$ acauado de pintar y Haze Las d[ic] has nasçiones y bultos de barro dio ser y anima acada Vno por si asi alos hombres Como aLas mugeres y Lesmando se sumiesen Debajo de tierra cada naçion por si y que de alli cada naçion fuese a salir A las partes y lugares que eL Los mandase que altiempo que El haçedor estaua en tia Huanaco diçen que era de noche y que alli hizo El sol y luna y estrellas y que mando al sol y luna y estrellas fuesen ala isla De titicaca y que desde alli suuiesen al cielo y que al tiempo que se queria Suuir El sol en figura de vn Hombre muy Resplandeçiente llamo a los yngas y a mango capac como a mayor dellos y le dixo

"tu y tus deçendientes aueis deser señores y aueis de sujetar muchas naçiones tenedme porpadre y por tales hijos mios os Jatad y asi me rreuerençiareis como apadre" $y$ que acauado de deçer esto a mango capac les dio por insinias y armas el sumptur paucar y el champi y otras insinias y que en aquel punto mando al sol Luna y estrellas Se suuiesen al çielo A ponerse cada Vno en sus Lugares y asi suuieron y se pusieron $y$ que luego en aquel instante mango capac $Y$ Sus hermanos y hermanas por mandado del haçedor se sumieron deuajo de tierra y uenieron asalir ala queba de paCa [2v] cari Tambo y que salieron al punto que el sol El primero dia despues de auer diuidodo la noche del dia el açedor y asi de aqui les quedo apellido de llamarse hijos del sol $y$ como padre adorarle y reuerenciarle.

Algunas frases parecen resúmenes de informaciones que deberían estar en el texto, como el Manqu Qhapaq y sus hermanos. Otras pueden ser ampliaciones introducidas por Christoual de Molina que no he logrado reconocer como tales. A pesar de todas las dudas, el contenido de la tabla o de las tablas incluía las expresiones siguientes:

a cada nación, a cada uno por sí, a la cueva de, a la isla, a la luna, a las partes y lugares, a los incas, a mango capac, a ponerse, a salir, acabado de hacer, acabado de pintar, 
adorarle, aguas, al cielo, al punto que, al sol, al tiempo, asi a los hombres, cada, cada uno, cantos, cerros, champi, comidas, como a las mujeres, como a mayor de ellos, como a padre, con cabello, concluído, cortado el cabello, cosa, cosas criadas, de alli, de atambor, de llamarse, de suerte, de tal manera, de un hombre, debajo de, del día, del hacedor, del sol, desde alli, después de haber dividido, día, dicen que era de noche, dichas naciones y bultos de barro, dio, dio ser y anima, empezó hacer, en aquel punto, en caja, en el mundo, en esta tierra, en figura, en sus lugares, en Tia Huanaco, estrellas, excepto, fuesen, gentes, habeis de ser señores, hacedor, hecho a estos, hijos, hizo, hombre, insignias, lengua, les dio, les mando, les mando se sumiesen, les quedo apellido, llamo, los mas altos, los que cortado [el cabello], los que habian de traer cabellos, mango capac, muchas, mujer, muy resplandeciente, nación, nacion por sí, naciones, noche, os jactad, otras, Pacari Tambo, pintándoles, por insignias, por mandado, por mitimas, por padre, primero, que alli quedasen, que el los mandase, que estaba, que fuese, que había de hablar, que había de traer y tener, que habian, que habian de cantar, que habían de sembrar, que hay, que mando, que no quedo, que quedaron, que se queria subir, que subieron, que subiesen, salieron, se subiesen, se sumieron, simientes, sobre, sol, sumptur paucar, tenedme, tierra, Titi Caca, todas, trajes y vestidos, tu, viento, viva, y a las estrellas, y así de aquí, y así me reverenciareis, y así subieron, $y$ como padre, $y$ dicen que en el perecieron, $y$ habeis de sujetar, y haciendo de barro, $y$ le dijo, y por armas, y por tales hijos míos, y que acabado de decir esto, y que al tiempo que se recogieron, y que allí, y que alli en Tia Huanaco, y que luego en aquel instante, $y$ que mando, $y$ reverenciarle, $y$ se pusieron, $y$ sus hermanas, $y$ sus hermanos, $y$ tus descendientes, $y$ vinieron a salir.

Dividí el texto en unidades no de acuerdo al texto castellano de Christoual de Molina, sino de acuerdo a la sintaxis quechua, según la cual una expresión como "y que al tiempo que se recogieron" puede ser una sola palabra. Una revisión de los ejemplos sugiere que el lector de la tabla que contenía la vida de Manqu Qhapaq leía en ella nombres propios, adjetivos y sustantivos, y también verbos en formas diversas. Resulta entonces que las qillqas de Puqin Kancha solamente en vida de Manqu Qhapaq Inqa contenían signos fonéticos al lado de los ideogramas. Todo esto sugiere que la escritura de Qulla Suyu puede tener algo en común con las tablas Puqin Kancha, y quizás con las letras mencionadas por Montesinos.

Las tablas mencionadas por Christoual de Molina, que quizás aún existían en 1572, desaparecieron sin dejar huella. Sin embargo, sus afirmaciones indican que las tablas pintadas no fueron un objeto de uso común y diario, y que fueron conservadas en templos o quizás en un solo templo, el de Puqin Kancha, en Cuzco. Esto no dice nada sobre otros Cuzcos y otras capitales imperiales.

Los que opinan que en Tawantin Suyu no existía la escritura tienen mucha razón al indicar la ausencia de inscripciones conservadas hasta nuestros tiempos. 
Los partidarios de una escritura andina opinan que tales inscripciones se conservan en forma de signos en tejidos y en qirus. Los signos rectangulares complicados y abstractos se llaman t'uqapu.

Hasta ahora, en la discusión no se ha tomado en cuenta los textos de catequesis en quechua y aymara que se usan hasta hoy día en Bolivia. Los textos contienen oraciones básicas y diversas variantes del catecismo. Los textos fueron usados y escritos por catequistas rurales en los siglos diecinueve y veinte. Sus autores raras veces eran curas, y en la mayoría de los casos eran personas que ni sabían el castellano ni el alfabeto latino. Entre los investigadores de aquellos textos ha arraigado la convicción de que los textos son fruto de la catequesis conducida por frailes franciscanos en el siglo dieciséis. Se suele afirmar que los frailes franciscanos, que en México habían aprovechado la pictografía náhuatl para catequizar a los aztecas, en Perú inventaron una pictografía andina para catequizar a los andinos en quechua y en aymara. La única excepción es el libro de Dick Ibarra Grasso (1953), cuyo autor afirma que la pictografía catequista es una herencia de una escritura andina precolombina.

Desafortunadamente los investigadores interesados no han preparado ni siquiera un catálogo de signos. Tampoco han descrito las reglas para construir los signos y las inscripciones. Lo publicado se reduce a fotos de inscripciones comentadas, a veces acompañadas por una notación en alfabeto latino de una lectura proporcionada por un especialista local. En algunos casos los especialistas o el investigador escribieron con los signos el himno de Bolivia u otro texto breve, pero en esto, a mi saber, acaba el estudio de las pictografías bolivianas.

Aquí presento los resultados de una investigación de los textos catequistas en quechua. La comencé en 2008. Recogí los textos publicados. Danuta Szemińska fotografió los textos conservados en museos de La Paz y Sucre. Mariusz Ziółkowski también compartió conmigo las fotos de todos los textos que había encontrado. El Instituto de Espacio Cívico en la Escuela Superior de Comercio y Derecho "Łazarski" de Varsovia financió una parte de la investigación en 2008-2009. Otra parte la financió la Universidad Hebrea de Jerusalén y un proyecto de investigación de los t’uqapu, dirigido por Mariusz Ziółkowski, en el cual participamos también Jarosław Arabas y yo.

Desafortunadamente, durante mi estadía en Cochabamba no logré ver los textos recogidos por Dick Ibarra Grasso en los años cincuenta del siglo veinte, conservados en el museo de la universidad, cerrado en aquel tiempo por miedo a la gripe porcina.

He investigado solamente textos en quechua. No conozco el aymara. El objetivo del presente artículo es mostrar ejemplos de textos, analizar su forma, proponer una clasificación de signos, indicar elementos arcaicos que ocurren entre los signos, sugerir el origen del sistema de pictografía boliviana actual y proponer un modelo de su funcionamiento en el pasado. 


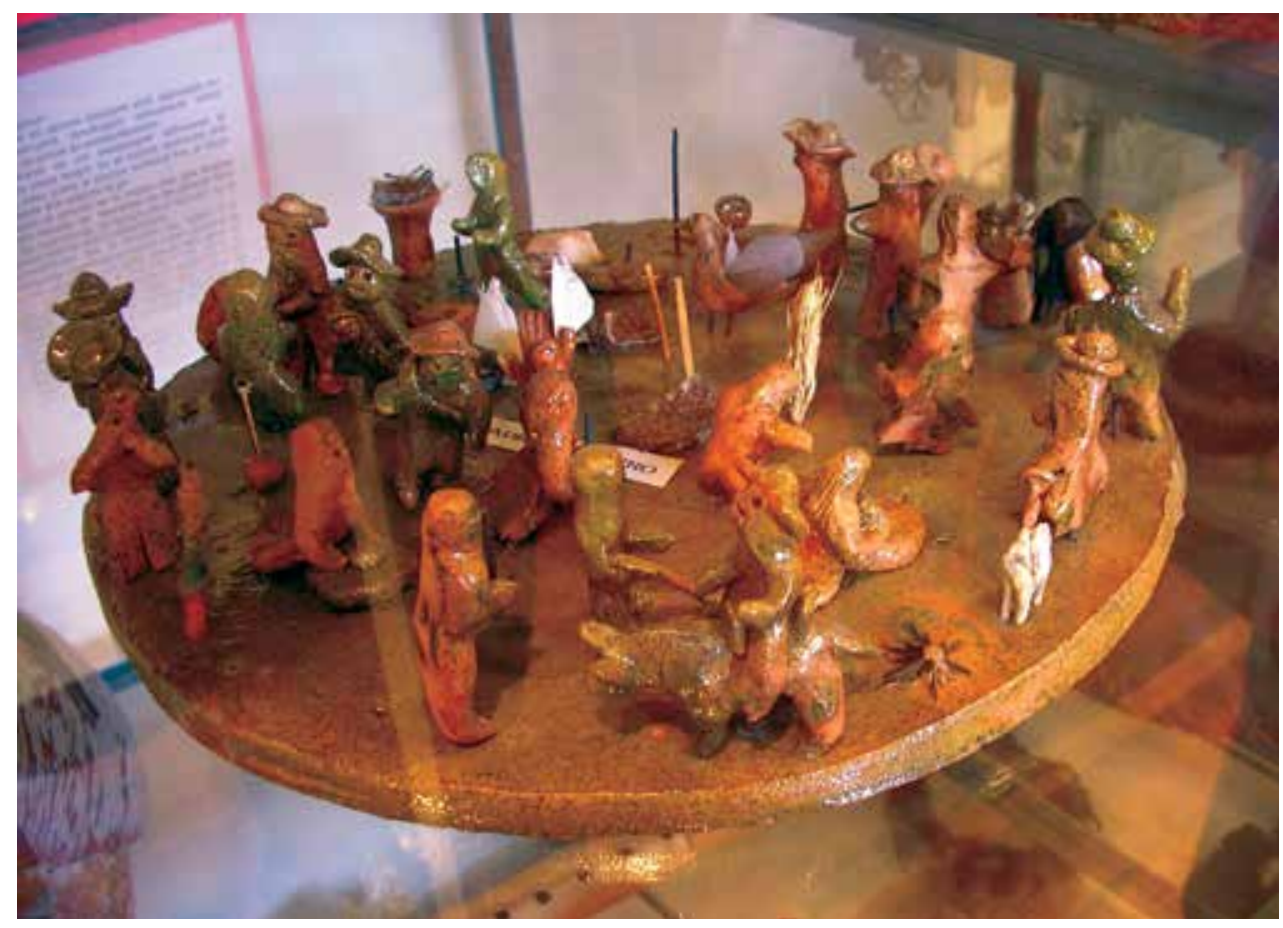

Figura 1. Pizza del Museo Arqueológico de la Universidad San Javier de Sucre.

\section{Las formas de notación}

En el siglo veinte existieron seis formas de notación. Las describiré a continuación.

Pizza

Una informante que encontré en un mercado de Sucre en 2009 me mostró cómo debe leerse un texto escrito con signos y acompañado con una transcripción en alfabeto latino. Afirmó que las pizzas de arcilla son la forma más antigua y más bella de escribir. En una tortilla de arcilla, en forma espiral desde el borde hacia el centro, aparece una secuencia de figuritas de arcilla, piedritas, pedazos de plantas y muchos otros componentes, como se ve en la Figura 1, que contiene un Padre Nuestro en quechua. Leído en el dialecto local del quechua, el texto debe sonar así:

¡Yayayku hanaq pachakunapi kaq! Sutiyki muchasqa kachun. Qhapaq kayniyki ñuqaykuman hamuchun. Munayniyki ruwasqa kachun, imayna hanaq pachapi, hi- 


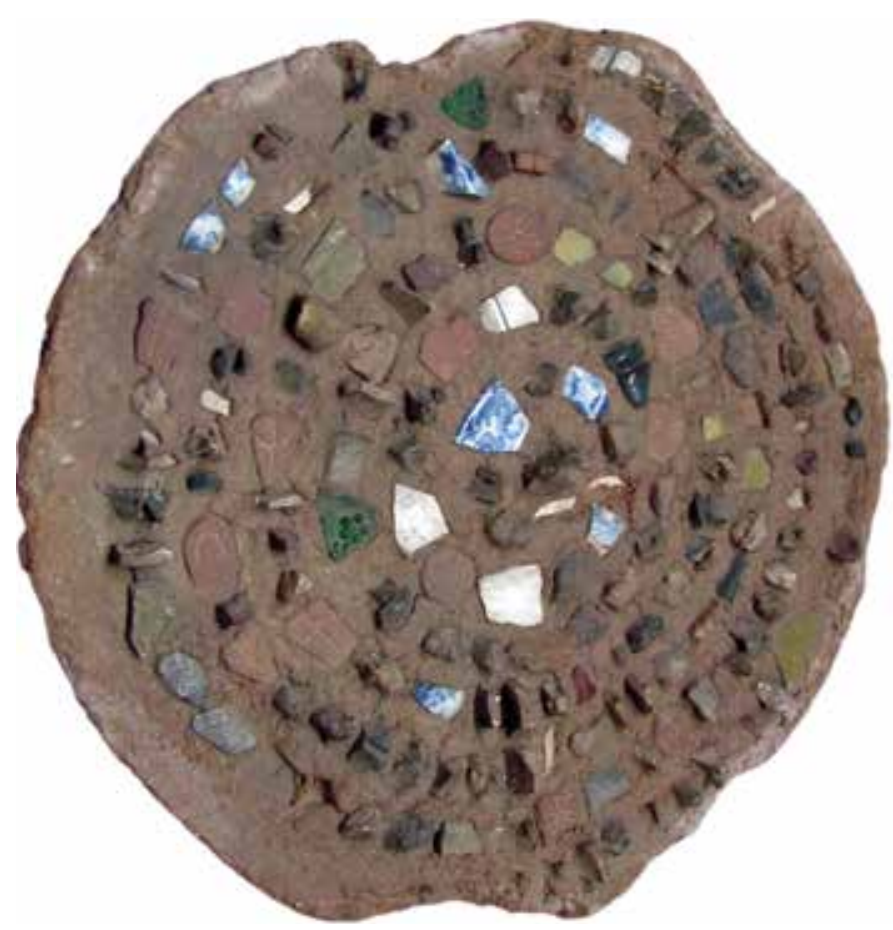

Figura 2. Pizza del Museo de la Universidad de Cochabamba.

nataq kay pachapipis. Sapa p’unchay t'antaykuta kunan qupuwayku, huchaykutari pampachapuwaykutaq, imaynachus ñuqaykupi ñuqaykuman huchallikuqkunata pampachaykutaq hina. Amataq saqiwaykuchu watiq kayman urmaqta, astawan saqramantari qhispichiwaykutaq. Amén ${ }^{1}$.

En el estado actual de la investigación no puedo analizar las pizzas. Su lectura exige saberes de un campesino local criado en la cultura tradicional de la región, por ejemplo chuquisaqueña. Como no soy ni seré un campesino chuquisaqueño o cochabambino no puedo sustituir a tal lector.

Las pizzas fueron observadas por los investigadores y viajeros durante el siglo diecinueve y veinte. Sin embargo, dos investigadores de la cultura andina del siglo dieciséis observaron un fenómeno igual o muy parecido. El jesuita Joseph de Acosta en 1590 en Sevilla publicó Historia natural y moral de las Indias, en que se tratan las cosas notables del cielo, y elementos, metales, plantas y animales dellas $y$ ritos y ceremonias, leyes y gobierno, y guerras de los indios. En el libro sexto, capitulo octavo dice:

\footnotetext{
${ }^{1}$ En el artículo uso la ortografía cuzqueña.
} 
Fuera de estos quipos de hilo, tienen otros de pedrezuelas, por donde puntualmente aprenden las plabras que quieren tomar de memoria. Y es cosa de ver a viejos ya caducos con una rueda hecha de pedrezuelas, aprender el Padre Nuestro, y con otra el Ave María, y con otra el Credo, y saber cuál piedra es que fué concebido de Espíritu Santo, y cuál que padeció debajo del poder de Poncio Pilato, y no hay más que verlos enmendar cuando yerran, y toda la enmienda consiste en mirar sus pedrezuelas, que a mí para hacerme olvidar cuanto sé de coro, me bastará una rueda de aquellas. De esta suele haber no pocas en lo cimenterios de las iglesias, para este efecto. [Acosta 1590/1979:291].

Su descripción puede referirse a la pizza siguiente, conservada en el Museo de la Universidad en Cochabamba (Figura 2). Como se ve, es una inscripción construida de pedrezuelas.

Son unas observaciones fundamentales. El jesuita explica que en siglo dieciséis las pizzas fueron usadas para anotar oraciones, como hoy. No sabemos en qué se diferenciaban de las tortillas cubiertas con figuritas de arcilla, pero, igual que hoy día, había una rueda diferente para cada oración. Su lugar - los cementeriossugiere una conexión con el culto de los antepasados, pero ya enterrados según la manera cristiana y española.

El segundo investigador es el Inca Garcilaso de la Vega, que en sus Comentarios Reales de los Incas observó:

La astrología y la filosofía natural que los Incas alanzaron fue muy poca. Porque como no tuvieron letras (aunque entre ellos hubo hombres de buenos ingenios - que llamaron amautas - que filosofaron cosas sutiles, como muchas que en su república platicaron), no pudiendo dejarlas escritas para que los sucesores las llevaran adelante perecieron con los mismos inventores. Así quedaron cortos en todas las ciencias o no las tuvieron, sino algunos rastreados con la lumbre natural. Y esos dejaron señalados con señales toscas y groseras para que las gentes las viesen y notasen. Diremos de cada cosa lo que tuvieron" [libro II, capitulo XXI].

Su observación puede referirse a signos en las pizzas, que son unas "señales toscas y groseras para que las gentes las viesen y notasen". A la vez indica que los amawtas usaban las "señales" para la "astrología y la filosofía natural”, ambos temas de la religión y la investigación del futuro.

\section{Espiral}

Aparte de las pizzas, en los museos se encuentran inscripciones en cuero o en papel. La forma más cercana a la de las tortillas son los signos escritos en 


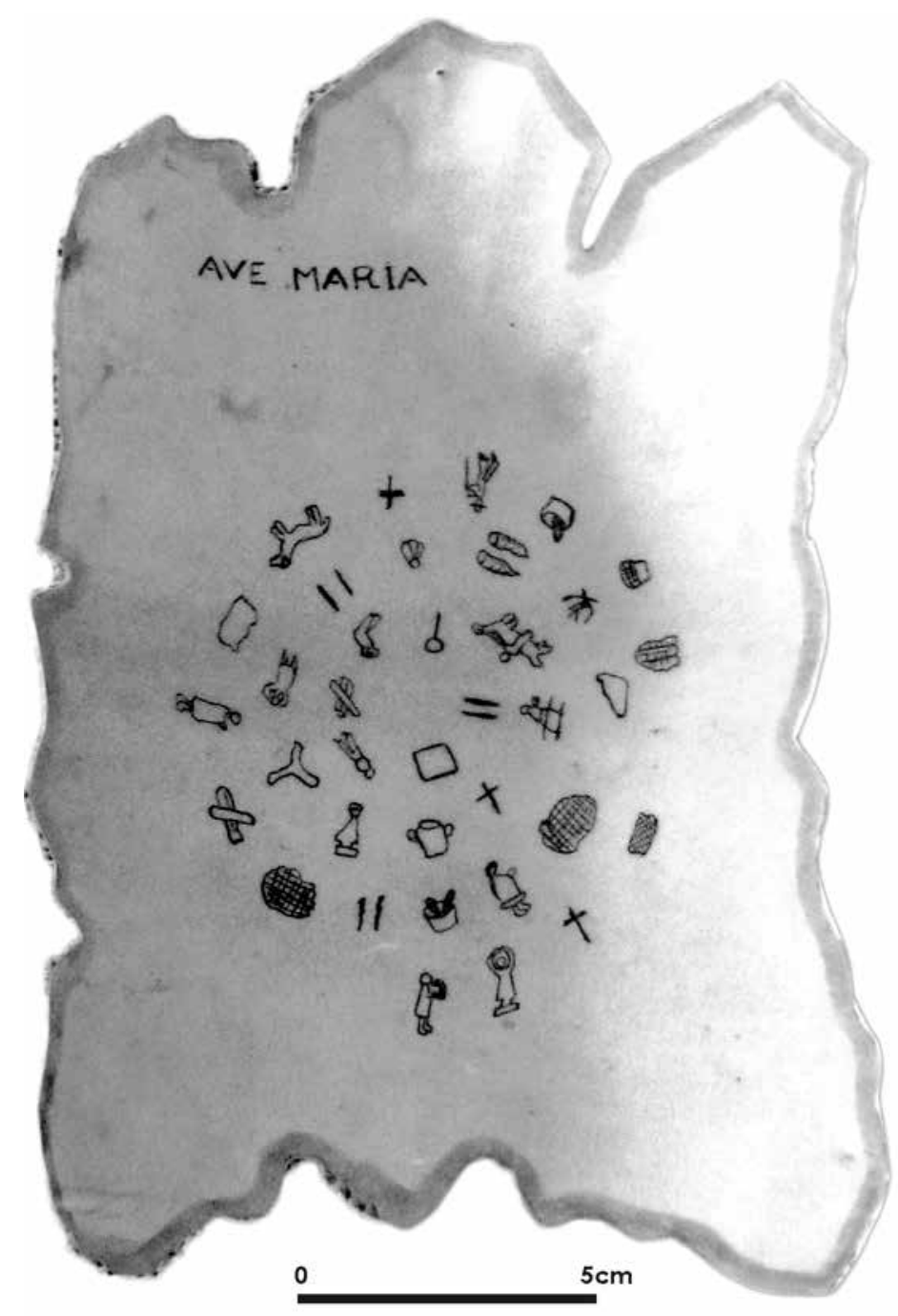

Figura 3. Espiral del Museo Arqueológico de la Universidad de Sucre.

espiral, desde el borde hacia el centro de la hoja. He aquí un ejemplo del Museo Arqueológico de la Universidad de Sucre (Figura 3). El Ave María en quechua local suena así:

Napaykuyki, Maria, Diuspa kanchayninwan huntasqan kanki. Apunchik qanwan. Tukuy warmikunamanta qullanamin kanki, wiksaykimanta paqarimuq Jesus wawaykiri qullanataqmin. iLlumpaq Maria Diuspa Maman! ñuqayku huchasapakunapaq mañapuwayku kunan wañuyniyku pachapiwanpas. Amén 
De Cochabamba proviene la siguiente versión del Padre Nuestro:

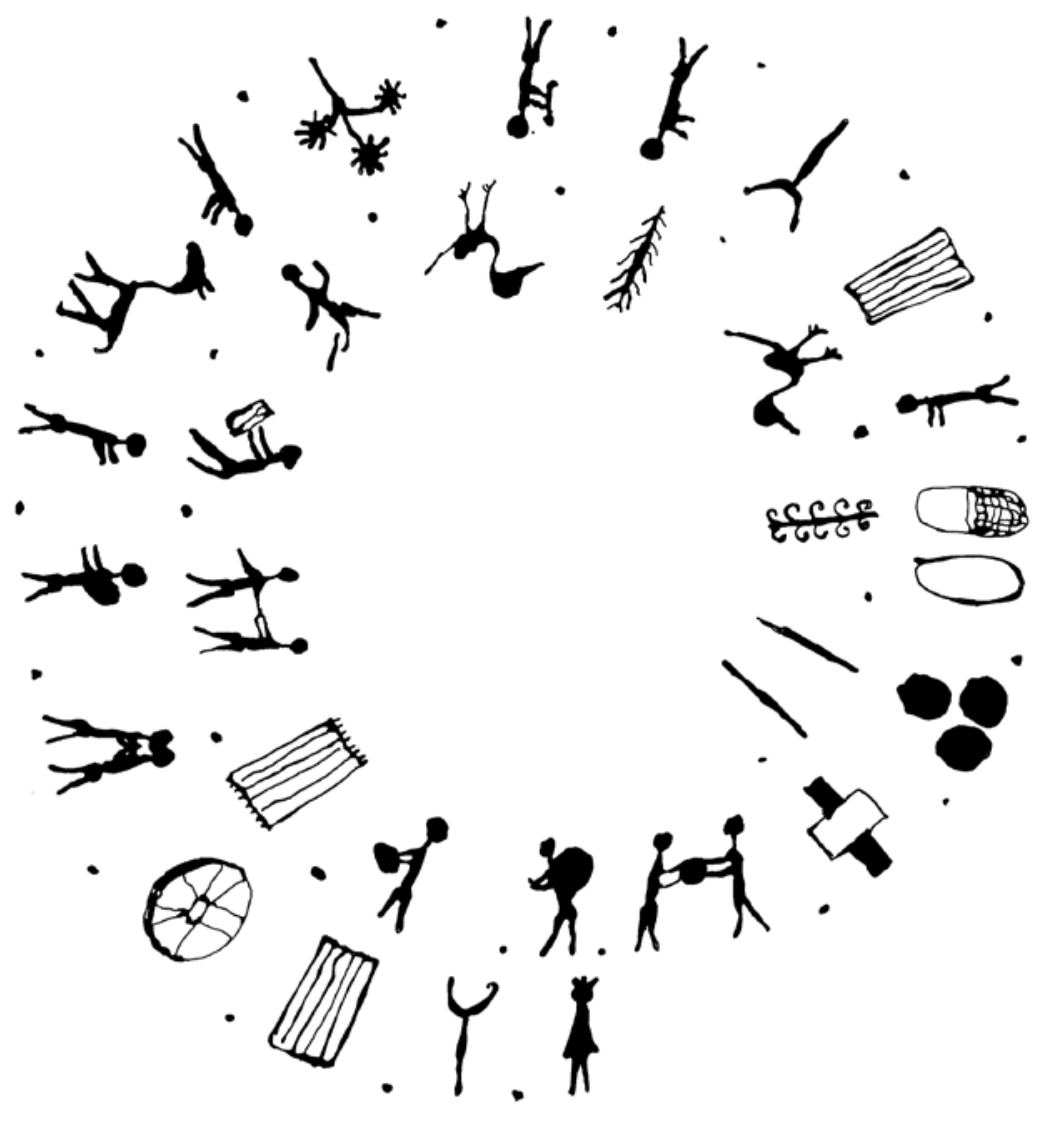

Los autores de la publicación, Walter Sánchez C. y Ramón Sanzetenea R. (2000), no llamaron la atención sobre el hecho de que en las pizzas el texto avanza desde la derecha hacia arriba y no hacia abajo, como en el ejemplo presente. Esto no influye en el valor de la publicación, una de las pocas en la cual todos los signos están provistos de una lectura en quechua y de una traducción castellana. El manuscrito es muy cuidado, con signos y grupos de signos separados con puntos.

No dudo que las espirales formadas de signos de arcilla o de pedrezuelas encima de una tortilla de arcilla y las espirales de signos en pergamino o papel sean dos formas de la misma tradición. El testimonio de Joseph de Acosta sugiere que las inscripciones en cuero o en papel son más recientes. Los signos escritos son una simplificación de los signos formados en arcilla. ¿Vale lo mismo para las pizzas formadas de pedrezuelas? 


\section{Bustrofedon}

Bajo la influencia de la escritura española colonial o postcolonial aparecieron también inscripciones en renglones. Probablemente las más antiguas sean aquellas donde el texto comienza en la esquina inferior derecha y la dirección del texto cambia en cada renglón. (1953:189):

Un buen ejemplo es un Padre Nuestro publicado por Dick Ibarra Grasso

7

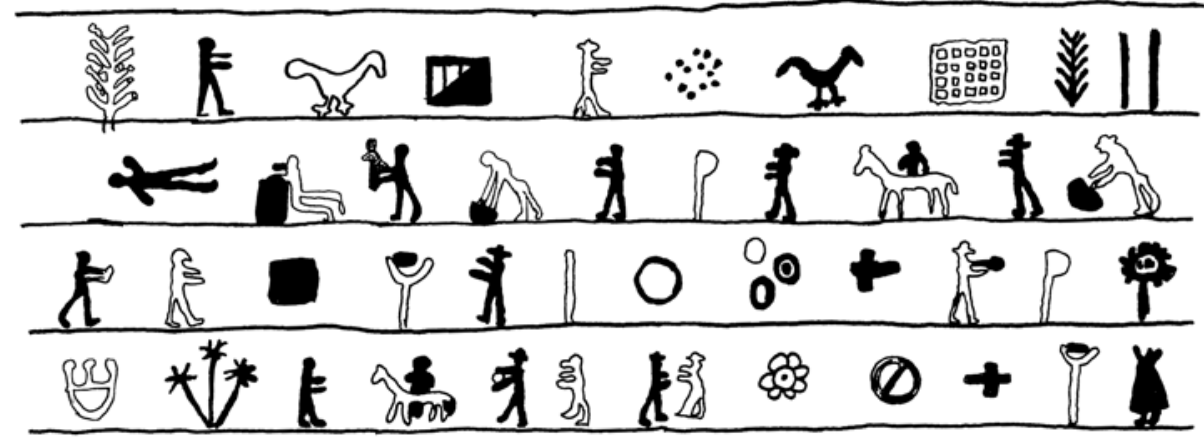

Existen también textos que comienzan arriba desde la izquierda, como en otro Padre Nuestro también publicado por Dick Ibarra Grasso (1953:223):

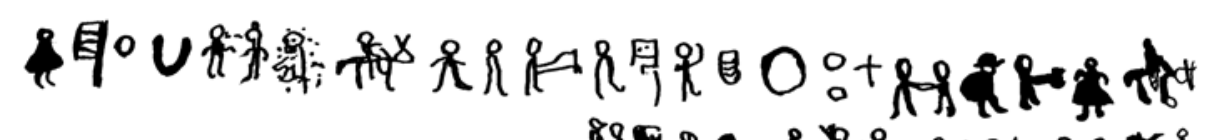 T)}

Cada texto proviene de un escribano y un lugar distintos. Finalmente aparecieron también textos que imitan la secuenciación de un texto castellano. Conozco un solo libro impreso que contiene textos paralelos, en pictografía y lo mismo en alfabeto latino, en quechua, publicado en Sucre en 1988, con imprimátur del arzobispo. Según el arzobispo, los signos fueron inventados por los misioneros. El libro Catecismo Diuswan munanakuypi kawsanapaj fue redactado por el padre Juan Miranda Mendoza con ayuda de un grupo de catequistas. En la foto de una oración se observa el orden de los signos tomado del castellano, desde arriba a la izquierda hacia la derecha. El texto muestra también el uso del color. Ya Dick Ibarra Grasso mencionó el uso de colores, que no se ve en las fotos que publicó. Los textos conservados en museos unos son policromos, otros monocromos: 


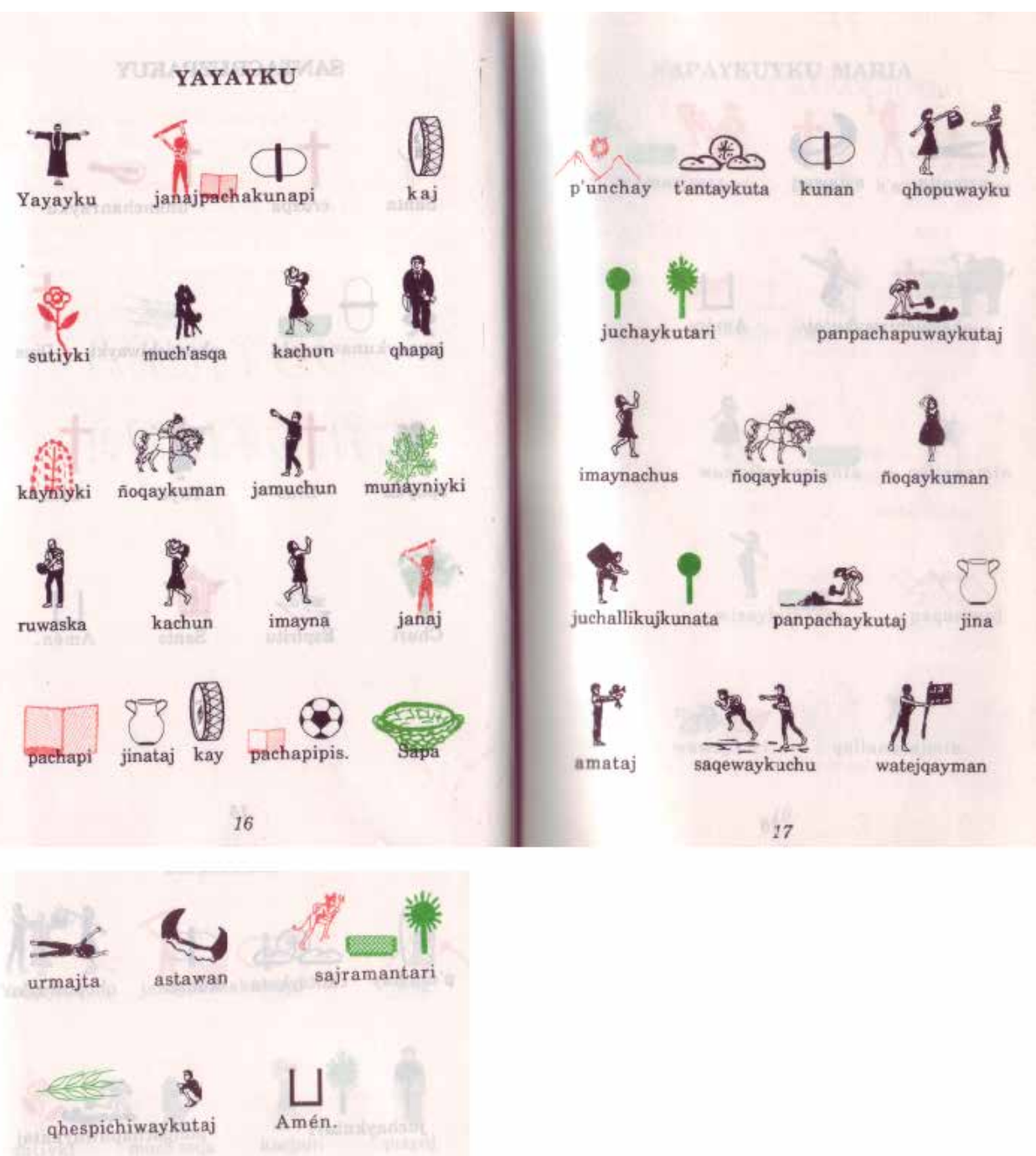

\section{Chiwchi recado y otros signos}

En el mercado de Cuzco y en otros lugares se venden paquetitos llenos de unos símbolos hechos de estaño. Las vendedoras cuzqueñas no supieron decirme los significados de los signos. Un paquetito se suele añadir a las ofrendas prefabricadas en el mercado destinadas a Pacha Mama o a los Apus. Me llama la atención el hecho de que no he visto que tales paquetitos se mencionen en las descripciones de ofrendas hechas por los antropólogos durante sus observaciones participantes. En Cuzco los signos se llaman chiwchi recado, "un recado de pollitos o niñitos". 
He aquí el contenido escaneado de un paquetito que compré en el mercado de Cuzco en 2009:

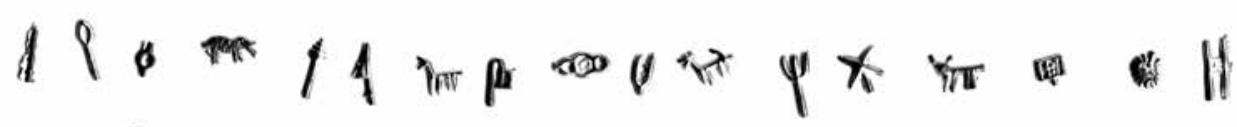

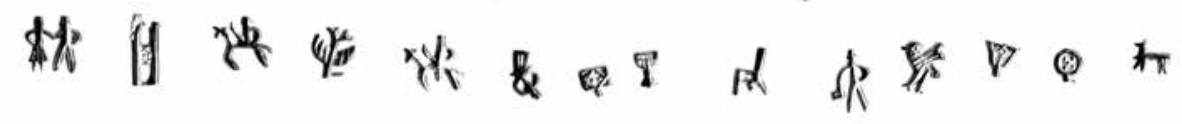 s. on}

Aparte de los chiwchi recados existen otros símbolos que se venden en los mercados y se usan en las ofrendas. Un buen ejemplo son los misterios, que se venden en el mercado de brujerías de La Paz. Son rectángulos hechos de azúcar, cada uno con un signo en la superficie del rectángulo. Cada misterio tiene su propio nombre, usualmente de un santo.

En los siglos dieciséis y diecisiete existieron también escudos incaicos y de grandes señores andinos. Parece que cada escudo describía el nombre y los títulos de su poseedor, lo que difiere de los escudos españoles, que representaban la genealogía de su propietario (Szemiński 1992).

\section{Conclusiones}

La revisión de los modos de anotar informaciones importantes, merecedoras de una "rueda de pedrezuelas" o de un escudo, indican que en el Tawantin Suyu del siglo dieciséis existieron varias formas de preservar informaciones, no solamente el khipu. Al lado de los signos t'uqapu, conocidos por los textiles y qirus, y al lado de las tablas pintadas probablemente llamadas qillqa, existían las "ruedas de pedrezuelas" y sus continuaciones con figuras de arcilla y signos en cuero y papel. Las ruedas de pedrezuelas y sus sucesores sirvieron y sirven para fines de catequesis, es decir para enseñar oraciones y saberes católicos. No se conocen otros usos sistemáticos, aunque se puede encontrar un himno nacional de Bolivia o una oración dirigida a una divinidad no admitida en el grupo de los santos católicos. Tales casos solamente indican la posibilidad de un uso más amplio, pero no atestiguan tal uso.

\section{¿Escritura u otra cosa?}

Los autores del siglo dieciséis, al describir el Perú, nunca dudaron que los peruanos no conocieron la escritura, igual que los mexicanos y los chinos; opinaban que solamente una escritura alfabética, como la latina, griega, hebrea o arábiga, era 
una escritura de verdad. Los investigadores modernos, de los siglos diecinueve y veinte, jamás dudaron de que las ruedas de pedrezuelas, o las tortillas con figuritas y los pergaminos con signos, eran un sistema pictográfico inventado por los misioneros, que se podía usar de la misma manera para catequizar en quechua, aymara o castellano. En el museo universitario en Cochabamba se encuentra la tabla siguiente, que ilustra y explica el modo de escribir textos catequéticos con la pictografía:
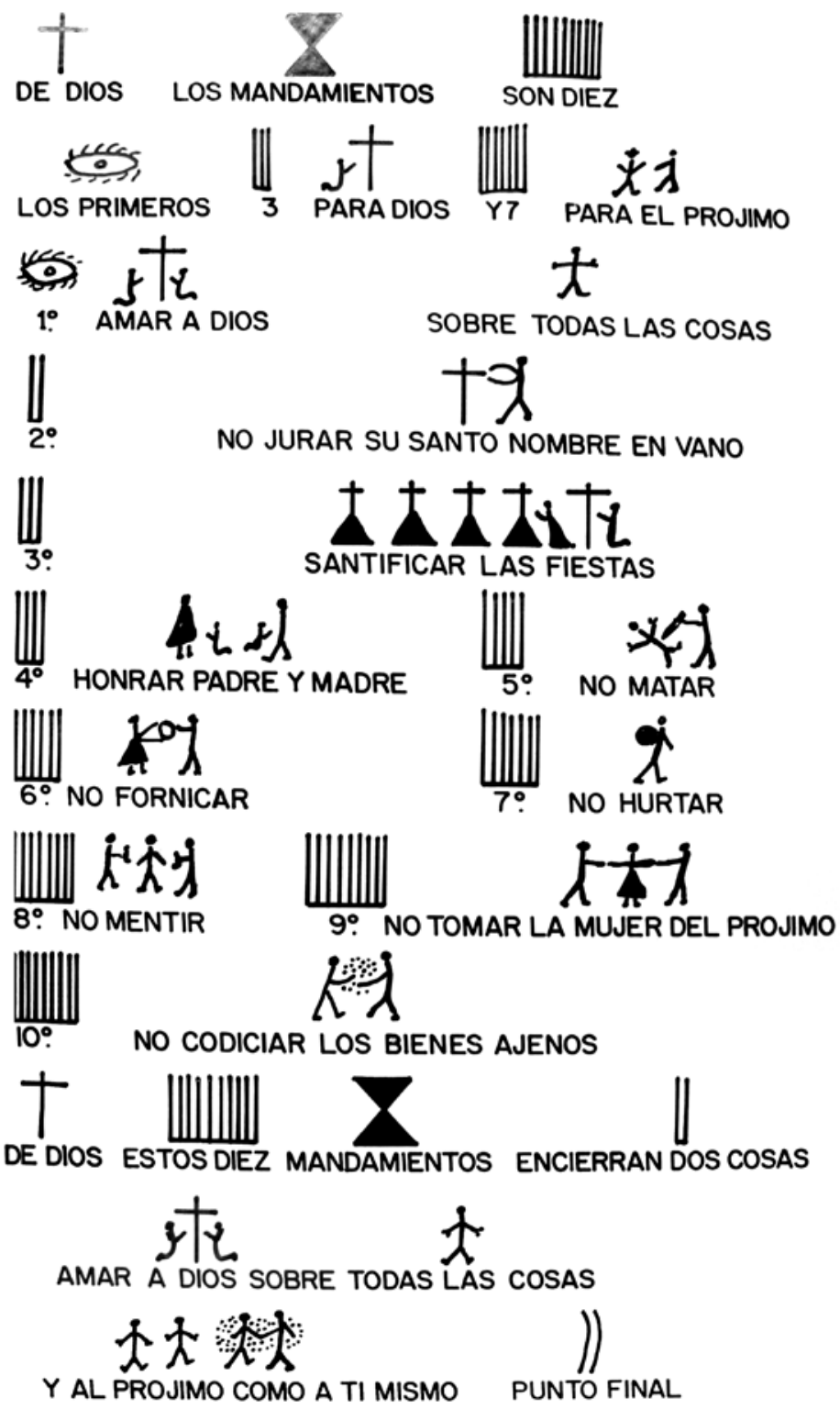
Los signos están explicados en castellano, pero el ejemplo fue tomado de un texto en quechua o en aymara, como lo demuestra el orden de las palabras, que no concuerda con la sintaxis castellana. Lo más sorprendente es que en los mandamientos no fue escrita con pictogramas la palabra no, presente en las explicaciones castellanas.

La tabla no es ningún argumento a favor de la existencia o no de una forma de notación, sea pictografía, logografía, silabografía o alfabeto, en quechua o aymara. Para saber de qué se trata es menester catalogar los signos y sus secuencias con el mayor número de ejemplos posible y con preferencia para textos largos. He comenzado a catalogar los signos aprovechando todos los textos que están acompañados por una lectura en quechua en alfabeto latino. Inmediatamente resultó que las diferencias entre un mismo texto, por ejemplo el Padre Nuestro, escrito por escribanos diferentes en lugares diferentes, son mucho mayores que las diferencias entre dos manos de dos escribanos que escriben el mismo texto en alfabeto latino. De hecho, las diferencias en el modo de escribir son por lo menos tan grandes como la diferencia entre el alfabeto latino y el hebreo. No se trata de un solo modo de anotar, sino de varios, similares pero diferentes. Cada uno de ellos se usaba o se usa en una comarca propia, donde los usuarios crearon su propia tradición de la notación. Mostraré tales diferencias al discutir ejemplos de los signos.

El modo de usar la notación le otorga ciertos rasgos. En este caso particular la notación no sirve para anotar y conservar informaciones nuevas, todavía fuera del conocimiento general, sino para facilitar y ayudar a recordar textos aprendidos por todos, que todos deben saber de memoria y usualmente los saben, ya que los aprendieron de niños, durante la catequesis básica. Los que les enseñan o enseñaron los saben y sabían de memoria, de otro modo no podrían cumplir con su deber de catequistas.

Los textos de catequesis básica fueron preparados en quechua y aymara en Lima e impresos ya en los años 1584-1585 como "Doctrina christiana y catecismo para instrucción de indios”, en ejecución de las decisiones del tercer concilio limence de 1582-1583. Las decisiones del concilio acabaron con los trabajos de diversos curas doctrineros, cada uno de los cuales había traducido por su cuenta oraciones e inventado terminología católica en quechua y aymara. Así, los textos de oraciones y de catequesis recibieron su forma canónica en ambas lenguas generales.

No se sabe si en aquel tiempo las autoridades eclesiásticas recomendaron o mandaron preparar "Doctrina christiana y catecismo para instrucción de indios" en otra forma de notación. Tampoco se sabe si lo hicieron frailes o monjes por su cuenta. La "Doctrina" fue reimpresa muchas veces, con cambios y adaptaciones, pero siempre en alfabeto latino. Su única impresión conocida hoy en signos no latinos proviene de 1988 .

Los curas se resistieron y no quisieron usar textos impresos en quechua o en aymara. Los que habían venido de los reinos de España opinaban que la exigen- 
cia de aprender el quechua o el aymara para servir como sacerdotes a la población local era una carga adicional, que los discriminaba frente a los curas criollos. Además, la catequesis en lengua local conducía - según su opinión - a malentendidos y herejías. Los curas criollos conocían las lenguas locales y las usaron en su trabajo, pero no consideraron necesario usarlas por escrito. En las cartillas escritas a mano o impresas, que contenían la doctrina cristiana y oraciones básicas, siempre se usó el alfabeto latino (Durston 2007).

El contenido de los textos no alfabéticos se corresponde muy bien con el contenido de las cartillas. Los autores de las cartillas fueron los curas. Los autores de los textos en "ruedas de pedrezuelas", pergaminos o cuadernos fueron los y las catequistas locales. Del siglo veinte se conocen ejemplos de "ruedas de pedrezuelas" producidas por curas.

En definitiva: al analizar los textos hay que tener en cuenta que sirven para enseñar y recordar al lector textos que el lector mismo ya conoce.

\section{Signos}

He analizado en total 1659 ocurrencias de signos. Todos los signos cuyos significado he logrado establecer pertenecen a una de tres categorías:

1. signos que se refieren a una frase entera o a una parte de la frase;

2. signos de significado o sonido;

3. signos que ayudan a entender los signos de significado o sonido, que los especialistas en escrituras jieroglíficas llaman signos determinativos.

Signos que se refieren a una frase entera o a una parte de la frase

He encontrado solamente dos signos de este tipo:

1. signo de final de oración o de frase;

2. signo de final de palabra o de una parte de la frase.

El signo de final de oración o de frase tiene forma de dos rayas paralelas verticales, a veces ligeramente curvas o unidas por una raya de base:

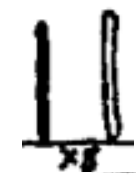

Dick Ibarra Grasso 1953:190.2.78,

Dick Ibarra Grasso 1953:247:151, 


\section{ப \\ Amén.}

Juan Miranda M. 1988: 27:18.

En finales de oraciones el signo se lee: Amén o Amén Jesús. Una sola vez apareció el signo compuesto de una sola raya vertical:

Dick Ibarra Grasso 1953:196.2.18,

al final de una oración dirigida a Hiqiqu, dios de la abundancia no reconocido por la Iglesia Católica.

El segundo signo, el de final de palabra o de una parte de una frase, apareció solamente en doce textos cochabambinos publicados por Walter Sánchez C. y Ramón Sanzetenea R.: Rogativas Andinas, Boletín del INIAN-Museo, Serie Antropología boliviana, No 8 enero febrero 2000, Cochabamba. Es un punto puesto después de un signo simple o un grupo de signos que se leen juntos:

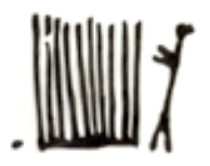

Walter Sánchez C. y Ramón Sanzetenea R. 2000:04.03.1.

El signo entero se lee kay chunka, de derecha a izquierda, y significa: estos diez, esta decena. Ambos signos sirven como signos de puntuación, que sugieren una entonación apropiada para leer los signos que preceden.

\section{Signos de significado o sonido}

Los signos que pertenecen a esta categoría se dejan dividir en muchos subgrupos. La división que propongo más abajo es preliminar y refleja el pésimo estado de investigación. A mi parecer se debe distinguir las clases siguientes:

1. pictogramas,

2. ideogramas,

3. jeroglíficos,

4. signos compuestos.

A continuación presentaré ejemplos de cada clase de signos. 


\section{Pictogramas}

Los pictogramas son signos que, dentro de las convenciones locales para dibujar, representan dibujos de cosas que existen y son vistas y conocidas por todos. Por ejemplo el pictograma zachia es un dibujo de un arbolito o arbusto, que se corresponde totalmente con el significado de la palabra zachia:

Walter Sánchez C. y Ramón Sanzetenea R. 2000: 01.02

Walter Sánchez C. y Ramón Sanzetenea R. 2000: 06.28.

A la clase de los pictogramas pertenece también el signo iglesia, que se lee de varias maneras. Por ejemplo:

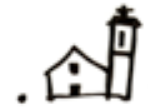

Walter Sánchez C. y Ramón Sanzetenea R. 2000: 03.12, que en este caso particular era leído iglesia punku, "la puerta de la iglesia", y no simplemente iglesia. En otro ejemplo:

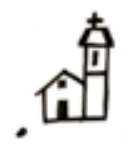

Walter Sánchez C. y Ramón Sanzetenea R. 2000: 08.41,

se lee: santa iglesia.

Ambos ejemplos demuestran que un pictograma puede ser a la vez un ideograma, es decir un dibujo de una idea. Para evitar la acusación de que los ejemplos de arriba son completamente europeos, miremos los pictogramas (y a la vez ideogramas) de la palabra simi, "boca, palabra mandamiento, orden". En mi corpus simi aparece 33 veces, pero en cada comarca el signo de simi es diferente:

Walter Sánchez C. y Ramón Sanzetenea R. 2000: 08.18.1. 
La primera parte del signo compuesto tiene forma de una $\mathrm{V}$ y se lee simi. La conexión entre la forma del signo y su significado, tan obvia en el caso de los signos zachia e iglesia, en el caso de simi está establecida por convenio y tiene que aprenderse, por lo menos según mi mirada de europeo.

El segundo signo leído simi está representado por un dibujo muy convencional de una mandíbula con 3 dientes que salen de ella, según el comentario de Dick Ibarra Graso. El signo puede leerse también kiru, "dientes":

Dick Ibarra Grasso 1953:192:003.

La elección del significado y sonido, simi o kiru, depende del contexto. El mismo signo aparece también en forma todavía más abstracta, que tiene que aprenderse:

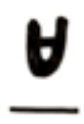

Dick Ibarra Grasso 1953:192:055.

En el único libro impreso aparece un dibujo de una boquita rosada, en un signo compuesto:

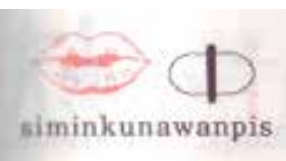

Juan Miranda M. 1988:25:04.1.

Este dibujo de la boca siempre se lee simi. Es muy importante advertir que cada signo aparece en un texto de una comarca diferente y en un grupo diferente de textos.

Los ejemplos de arriba indican que:

1. la frontera entre pictogramas e ideogramas es muy ambigua y la diferencia entre ellos quizás sea introducida por el investigador desde fuera;

2. los pictogramas son signos establecidos por la práctica de los ecribanos, la cual establece en una comarca determinada que el signo $\mathrm{V}$ se lee simi, y no de otra manera; 
3. para que aparezcan signos completamente convencionales y esta blecidos por el uso se necesita una interacción entre los usuarios que dura largo tiempo.

\section{Ideogramas}

Digamos que los ideogramas son signos que representan ideas y no objetos. En textos religiosos deben aparecer más veces que en una lista de compras. Tales signos pueden corresponderse con más de una palabra.

Ejemplo 1: bendicionta chura-

En una de las oraciones cochabambinas aparece una expresión que corresponde a bendecir en castellano. Los autores de la oración construyeron una expresión en quechua, bendicionta churayku-, que significa poner una bendición en un lugar que le corresponde. La expresión ha sido dibujada de la siguiente manera:

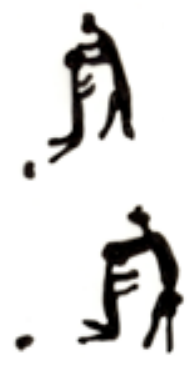

Walter Sánchez C. y Ramón Sanzetenea R. 2000:01:23,

Ambos dibujos se leen del mismo modo: bendicionta churaykuway, que significa: pon en mí la bendición. Alrededor del signo no hay otros que indiquen la forma que se debe dar al verbo, chura y al sustantivo, bendición, prestado del castellano.

Ejemplo 2: cruz, Dios, chakata

En los textos que he investigado el signo más frecuente es el de la cruz:

Walter Sánchez C. y Ramón Sanzetenea R. 2000:07:02.

Walter Sánchez C. y Ramón Sanzetenea R. 2000:02.18,

Dick Ibarra Grasso 1953:192:023, 
El signo se lee: Dios, cruz, Jesucristo, chakata, según el contexto. Chakata significa en quechua cruz y crucificar.

El signo de la cruz forma parte de signos compuestos, por ejemplo:

Diosmanta mañapuwayku, "De Dios pide para nosotros".

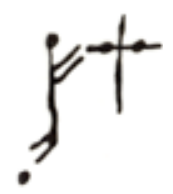

Walter Sánchez C. y Ramón Sanzetenea R. 2000:05.34.1;

cruznin q'ipirisqa, "cargado con la cruz".

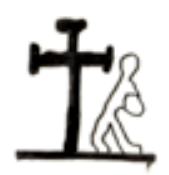

Dick Ibarra Grasso 1953:191:3:13.

Ejemplo 3: yupa, hunt'a

Después de casos tan simples que sirven para introducir el problema, quiero presentar aquí un signo mucho más difícil de interpretar:

Dick Ibarra Grasso 1953:192.011.

El signo forma parte de signos compuestos y probablemente no aparece solo. He aquí unos ejemplos:

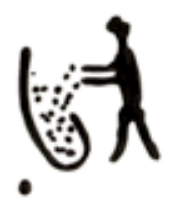

Walter Sánchez C. y Ramón Sanzetenea R. 2000:01.08.

Un hombre echa en un recipiente granos $\mathrm{u}$ otras cosas pequeñas y uniformes. En quechua el verbo yupaycha, "honrar", se deriva de la raíz yupa, "contar". El 
dibujo corresponde entonces al significado de la raíz yupa, "contar", y el lector añade los sufijos que le otorgan el significado de yupaychana, "lo que se debe honrar".

En otro texto el mismo signo:

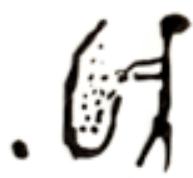

Walter Sánchez C. y Ramón Sanzetenea R. 2000:11.26,

ha sido leído como: huntasaqmi, "llenaré, cumpliré", y no yupaychasaqmi, "honraré", como parte de una frase que dice: "Cumpliré los mandamientos del confesor". Entonces en este caso el hombre no cuenta objetos echados al recipiente, sino solamente lo llena con ellos.

El signo que significa honrar, yupaycha-, en el texto de Juan Miranda M. no incluye recipiente. El dibujo consiste en una pareja que mira seis objetos iguales, dibujados como puntos:

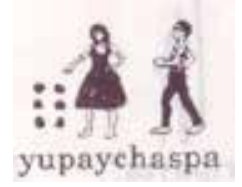

Juan Miranda M. 1988:31:15

Parece que la pareja cuenta los puntos. El texto en alfabeto latino reza: yupaychaspa, "honrando".

El recipiente desaparecido vuelve a la escena en el signo misterio, el secreto de la fe:

Misterio

Juan Miranda M. 1988:34.17.

La comparación de los dibujos y de los significados revela que los significados de los ideogramas son establecidos por el lector de acuerdo a:

1. contexto en el texto;

2. contexto cultural del lector.

Ejemplo 4: p’unchaw

Otro ejemplo de un ideograma es el signo p’unchaw, "día", que en el dialecto del lugar tiene la forma p’unchay. El día se suele dibujar así: 


\section{0}

Walter Sánchez C. y Ramón Sanzetenea R. 2000:02.05.

El signo se lee: p’unchaw.

.000

Walter Sánchez C. y Ramón Sanzetenea R. 2000:03.11.

El signo se lee: kimza paqarin, "tres mañanas", en vez de kimza p'unchaw, "tres días".

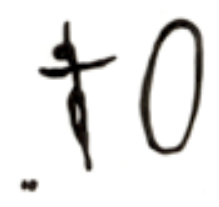

Walter Sánchez C. y Ramón Sanzetenea R. 2000:08.16.

El signo se lee paqarin Jesus, "nació Jesús". La lectura p’unchaw fue sustituida por la lectura paqarin, que significa: mañana, amanece, nace, amaneció, nació. En este signo compuesto Jesús esta dibujado como el crucificado y no como la cruz, más frecuente en mi corpus.

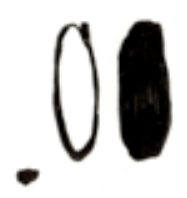

Walter Sánchez C. y Ramón Sanzetenea R. 2000:11.39.

El signo se lee tuta p’unchaw, "noche y día, veinticuatro horas". Merece subrayarse que el orden de signos y de palabras es muy andino y precristiano, ya que las veinticuatro horas andinas comienzan al atardecer, como entre judíos y moros, y no a media noche, como entre los cristianos. Ambos componentes, noche y día, están dibujados en forma de óvalos iguales, uno negro para la noche, otro blanco para el día.

Fuera del óvalo aparecen otros signos, quizás conectados con el sol y no con el día:

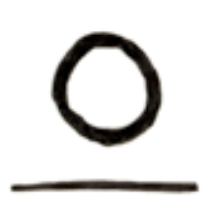

Dick Ibarra Grasso 1953:189.19. 
Dick Ibarra Grasso (1953:173) cree que el signo es inti, "sol", sin embargo en el texto se lee p’unchaw, “día”.

En otro texto también descrito por Dick Ibarra Grasso el signo tiene la forma de un sol con rayos:

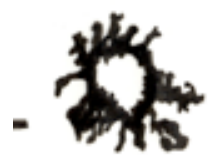

Dick Ibarra Grasso 1953:247:108

En el libro de Juan Miranda M., a quien la imprenta dio más posibilidades gráficas, aparece el dibujo siguiente:

\section{p'unchay}

Juan Miranda M. 1988:17:01,

que se lee p’unchaw, "día”, aunque por su forma de sol que se levanta o baja entre los cerros puede ser también paqarin, "mañana, nace, sube", o yaykun, "baja”.

Ejemplo 5: numerales

Una clase especial de ideogramas la constituyen los numerales. En textos quechuas casi siempre se escriben con líneas verticales paralelas y excepcionalmente con círculos. En textos aymaras he visto también triángulos. Las líneas verticales usualmente están unidas por una base común, lo cual da una impresión de un peine:

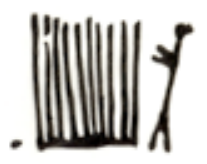

Walter Sánchez C. y Ramón Sanzetenea R. 2000:04.03.

El signo compuesto se lee: kay chunka, "estos diez, los diez, esta decena".

Me parece importante la manera de unir las líneas verticales con una base común, una línea horizontal. Tal manera es muy parecida a los nudos largos de los khipus, que servían para anotar unidades entre 2 y 9 . En el libro de Juan Miranda M. (1988:91-92) aparece el numeral chunka tawayuq, catorce, escrito con dos signos, uno como diez y otro como cuatro:

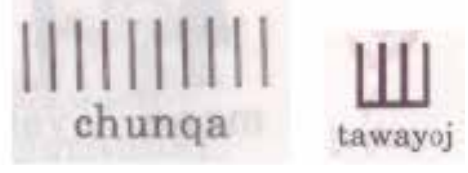


La decena está dibujada con diez rayas verticales sin unirlas en un nudo común, mientras que el cuatro tiene la forma tradicional, un nudo largo. Las notaciones de números en el khipu distinguían el uno con un nudo especial, usado para anudar el uno, y el número de decenas, centenas, miles y decenas de millar. Por ejemplo, nunca se anudaba el número 30 con un nudo largo de tres vueltas, sino con tres nudos de unidades uno al lado de otro en una posición de decenas. Aquí, en el texto de Miranda, la diferencia en la manera de anotar una decena frente a un cuatro parece indicar que en el pasado la decena fue escrita de otro modo, y no con 10 rayas. Encontré un solo ejemplo de notación diferente de una decena:
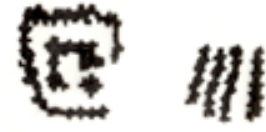

chunka tawayuq, "catorce”, Dick Ibarra Grasso 1953:247:007.

Cuatro esta escrito con rayas verticales y diez con un cuadrado en un cuadrado. La comparación de las notaciones quizás sugiere que el sistema de anotar números fue un reflejo del sistema usado en los khipus.

\section{Jeroglíficos}

No se conocen sistemas de escribir con pictogramas sin jeroglíficos, definidos por el Diccionario de la Real Academia como: "Conjunto de signos y figuras con que se expresa una frase, ordinariamente por pasatiempo o juego de ingenio". Precisamente el juego de ingenio permite dibujar una cosa y leer otra, donde el dibujo sugiere asociaciones usualmente fonéticas. En la notación estudiada los jeroglíficos aparecen continuamente. Para describirlos hay que distinguir tres clases de jeroglíficos, y en cada clase dos maneras de usar el jeroglífico. Las raíces quechuas son normalmente bisilábicas. En los jeroglíficos se aprovecha ya ambas sílabas, ya una sola, más bien la primera, aunque los casos no son muy claros.

Los jeroglíficos quechuas en Qulla Suyu, es decir en la Bolivia de hoy, funcionan en una sociedad donde coexisten tres lenguas: el quechua, el aymara y el castellano. En tierras de habla quechua aparecen también grupos aymaras. En toda el área de lengua quechua muchas personas hablan el castellano y frecuentemente prefieren el castellano.

Para entender los jeroglíficos es menester conocer los fonemas y la estructura silábica del quechua, aymara y castellano. El quechua y el aymara en Bolivia tienen los mismos fonemas, con la diferencia de que las vocales aymaras pueden ser largas o breves, mientras que las vocales quechuas no pueden ser largas. El aymara tolera secuencias de más que dos consonantes dentro de una palabra, mientras que el quechua tolera solamente grupos de dos consonantes, obligatoriamente precedi- 
das y seguidas por una vocal. En aymara existe un sistema muy complejo para elidir vocales dentro de una palabra según, las propiedades de los sufijos y la posición de la palabra dentro de una frase. En quechua tales fenómenos no existen.

La tabla presenta las consonantes del quechua y del aymara en los dialectos usados en Bolivia:

\begin{tabular}{|c|c|c|c|c|}
\hline $\mathrm{p}$ & $\mathrm{t}$ & $\mathrm{ch}$ & $\mathrm{k}$ & $\mathrm{q}$ \\
\hline $\mathrm{p}^{\mathrm{c}}$ & $\mathrm{t}^{\mathrm{c}}$ & $\mathrm{ch}^{\mathrm{c}}$ & $\mathrm{k}^{\mathrm{c}}$ & $\mathrm{q}^{\mathrm{c}}$ \\
\hline $\mathrm{ph}$ & $\mathrm{th}$ & $\mathrm{chh}$ & $\mathrm{kh}$ & $\mathrm{qh}$ \\
\hline & $\mathrm{z}^{*}$ & $\mathrm{~s}$ & $\mathrm{~h}$ & $\mathrm{x}$ \\
\hline $\mathrm{w}$ & $\mathrm{l}$ & $\mathrm{ll}$ & $\mathrm{y}$ & \\
\hline $\mathrm{m}$ & $\mathrm{r}$ & & & \\
\hline
\end{tabular}

* En el siglo XVI en quechua existieron dos consonantes aquí marcadas con s y z, que en mayoria de dialectos modernos se convirtieron en una sola s. En aymara existe una sola s.

Aparecen sustituciones entre: $p: p^{\dagger}: p h:, t: t^{\dagger}: t h: z, c h: c h: c h: s, k: k^{\varsigma}: k h, q: q^{\dagger}: q h, z: s$, $h: x, w: y, l: r, n: \tilde{n} ; \tilde{n}: l l$, y a veces: $k: q$. Las sustituciones significan que una palabra que en un dialecto contiene, por ejemplo, una consonante $p h$, puede en otro dialecto contener en el mismo lugar $p^{\prime} \mathrm{o} p$. Tales sustituciones son importantes para entender la construcción de los jeroglíficos y sus significados.

\section{Jeroglificos quechuas-quechuas}

Tales jeroglíficos consisten en leer una palabra quechua en vez de otra palabra quechua representada por el signo, cuyo sonido es similar a la palabra dibujada.

Ejemplo 1: ñuqa

Un buen ejemplo de sustitución es la manera de escribir los pronombres de primera persona: ñuqa, "yo", ñuqayku, "nosotros sin ti", y cuarta persona: ñuqanchik, "tu y yo". Para esto sirve un dibujo de caballero o de una persona que sube al caballo:

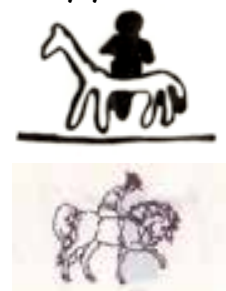

Dick Ibarra Grasso 1953:189:09, 
Ambos ejemplos se leen: ñuqaykuman, "a nosotros sin ti". Subir a un caballo, trepar a las rodillas de una persona como lo hace un niño, trepar a un cerro, todo esto se dice en quechua: lluqha, lluq'a o lluqa, según el dialecto. La sustitución de la primera consonante $l l$ en $\tilde{n}$ transforma la palabra en $\tilde{n} u q a, \tilde{n} u q a y k u, \tilde{n} u q a n c h i k$. Tal signo pudo aparecer solamente cuando ya se divulgaron los caballos y las mulas, es decir después de la conquista española.

Ejemplo 2: pacha

Otro ejemplo importante son los signos que se leen pacha, tiempo-espacio, un momento en el tiempo, un lugar en el espacio, en siglo dieciséis una de las cuatro partes del cosmos, y en siglo veinte una de las tres partes del cosmos: qaylla pacha, el mundo de los límites; hanaq pacha, el cielo y la gloria; kay pacha, este mundo en que vivimos; y $u k h u$ pacha, el mundo de adentro y de abajo, el mundo subterráneo, el de la oscuridad y de los muertos. En el corpus he encontrado los siguientes signos, todos leídos pacha:

1. Un rectángulo relleno de rayas verticales: - Walter Sánchez C. y Ramón Sanzetenea R. 2000:08:05, que se lee ya: pacha, ya: kay pacha.

2. Un cuadrado negro:

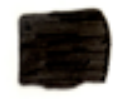

Según el comentario del autor es páacha, "vestido, ropa", que en este caso se lee kay pacha, "este mundo".

3. Un rectángulo de dos partes, cubierto de rayas: y con una mancha uniforme en una de las partes. Juan Miranda M. 1988:16:16. El signo parece un manto o una pieza textil, es decir otra vez p’acha, "vestido".

4. Un dibujo no muy claro, probablemente de un sapo o de una rana: Dick Ibarra Grasso 1953:247:089. Tradicionalmente el sapo hamp'atu representa a Pacha Mama, Madre del Cosmos o Madre Tierra, asociada con $u k h u$ pacha, el mundo subterráneo. En este caso el signo se lee $u k h u$ pachaman, "al mundo subterráneo, al infierno".

Tres de los signos son jeroglíficos basados en la similitud entre las palabras pacha y p’acha. El cuarto reenvía a un mito. ¿Existieron también signos de 
otras partes del cosmos basadas en mitos no cristianos? El sapo como símbolo de una parte del cosmos no proviene de una tradición cristiana. ¿De dónde proviene la asociación entre pacha y páacha? ¿Es un jeroglífico inventado por el hecho de que en la pronunciación castellana ambas palabras suenan igual, o un invento original andino?

Ejemplo 3: hanaq

Delante de pacha tiene que ir un adjetivo que explique de qué parte del cosmos se trata. Como los textos son textos de catequesis y durante la catequesis se habla del cielo y de la gloria, he hecho también una revisión de los signos leídos hanaq, "superior, el de arriba". He aquí dos ejemplos muy similares:

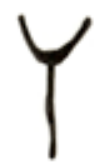

Walter Sánchez C. y Ramón Sanzetenea R. 2000:08.04

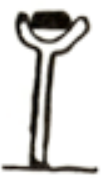

Dick Ibarra Grasso 1953:189:02,

Ambos signos han sido leídos hanaq pacha, "cielo". Dick Ibarra Grasso comenta el signo del modo siguiente: "un género, ppacha, sobre una especie de embudo, en realidad el 'disco' de la alta tierra sostenido por un palito" (Dick Ibarra Grasso 1953:72). Sin embargo, en Juan Miranda M. 1988:15.01 el signo se lee: santa.

El mismo autor escribe hanaq de otro modo:

\section{Santa}

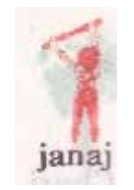

Juan Miranda M. 1988:16:15.

Una persona mantiene un palo con ambas manos encima de su cabeza. Parece que se trata de una versión del mismo signo que en los ejemplos primero y segundo de hanaq, pero sin simplificaciones.

La comparación de las versiones sugiere que es un signo establecido por el uso, y por tanto antiguo. 
Ejemplo 4: qam, allqu

Es también muy ilustrativa la notación del pronombre de segunda persona: tú, vos, vosotros, en quechua qam o qan. El signo siempre es un dibujito de un perro, en quechua allqu:
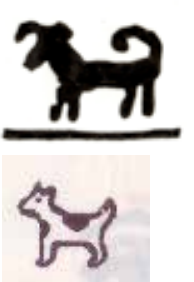

qanta
Dick Ibarra Grasso 1953:192:18;

Juan Miranda M. 1988:21:12.

Dick Ibarra Grasso 1953:179 explica que "kan-kan" es "la voz de perro". Desafortunadamente, en todos los vocabularios quechuas que he consultado no aparece nada similar a "kan-kan". Quizás se trata de una asociación con el ladrido del perro, que le grita a uno que no es miembro de la casa: qan, "tú", o qan-qan, "vosotros, el grupo de vosotros".

Ejemplo 5: muña, muna

En los jeroglíficos son muy frecuentes los nombres de plantas, como:

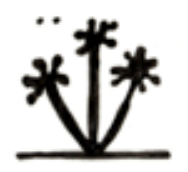

Dick Ibarra Grasso 1953:189:11,

quien identifica el signo como representación de la planta llamada muna-muna (Dick Ibarra Grasso 1953:172). Probablemente se trata de una de las diversas plantas llamadas muña o muña-muña. La misma planta aparece también en los textos de Juan Miranda M.:

y en las oraciones cochabambinas:

Walter Sánchez C. y Ramón Sanzetenea R. 2000:12.09.

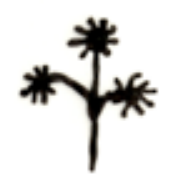


En cada caso se lee muna- con los sufijos necesarios. Muna- significa querer, amar, desear, voluntad.

Ejemplo 6: tara, tari

Otro caso del uso del nombre de un vegetal como jeroglífico es el signo que representa el arbolito tara, Caesalpinia spinosa:

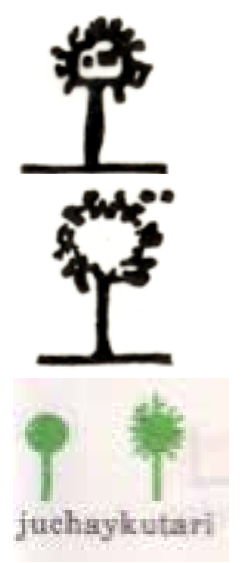

Dick Ibarra Grasso 1953:189:24;

Dick Ibarra Grasso 1953:190.1.59;

En todos los casos observados el signo se lee tari, ya como una secuencia de dos sufijos, ta-ri, ya como raíz tari, "encontrar, juzgar". La segunda vocal del nombre del arbolito, tara, resultó no tener importancia y quizás ha sido continuamente sustituida por una $i$, convirtiéndolo en tari. Como tal uso aparece en todos los textos analizados, parece un uso antiguo y bien establecido.

Ejemplo 7: suti, sut'u

Hay por lo menos dos signos diferentes para escribir la raíz suti, "nombre". El primero representa gotas de lluvia, el segundo una flor:

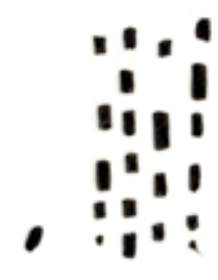

Walter Sánchez C. y Ramón Sanzetenea R. 2000:04.17; 
Dick Ibarra Grasso 1953: 189:05;

\section{$\$$}

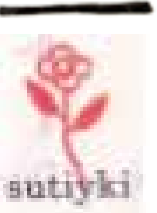

Juan Miranda M. 1988:16:04.

Fuera de la clasificación ha quedado un signo que no sé identificar:

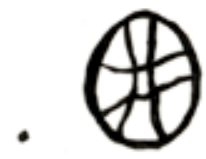

Walter Sánchez C. y Ramón Sanzetenea R. 2000:12:04,

Quizás es otra versión de la flor.

"Gota, gotear" se dice en quechua sut’u. Es un ejemplo más de sustitución, cuando la segunda sílaba es sustituida por otra: $t^{\prime} u->t i$.

No he logrado entender por qué una flor (en quechua: t'ika, wayta, ziza o ayna) se lee suti. En los vocabularios no he encontrado ningún nombre de una flor parecido a suti. Si tal nombre no existe, quizás el signo suti en forma de dibujito de una flor sea un signo establecido solamente por convenio y uso.

Los jeroglíficos quechuas aparentemente indican dos rasgos de notación:

1. existen signos fonéticos, establecidos o por similitud fonética entre dos palabras o de manera arbitraria;

2. los signos fonéticos, bisilábicos, se usan de tal modo que la segunda sílaba puede sustituirse con otra u omitirse.

Jeroglificos hispano-quechuas

Los jeroglíficos hispano-quechuas consisten en representar una palabra quechua con el dibujo de una palabra castellana que suena como una palabra o un morfema quechua.

Ejemplo 1: cama, kama

El dibujo de la palabra castellana cama sirve para escribir la raíz quechua kama, "hasta, mandar, dar fuerza vital". 
Kamachikusqan simi, "Los Mandamientos", Walter Sánchez C. y Ramón Sanzetenea R. 2000:04.02

El signo está compuesto de un rectángulo cubierto de rayas verticales y horizontales, que simboliza un catre o una cama, seguido del signo $\mathrm{V}$, simi, ya discutido más arriba. En este caso el lector añadió a cama diversos sufijos necesarios, y así el signo era leído kamachikusqan, "por él y de su voluntad mandado".

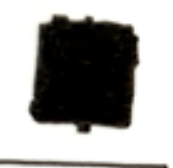

Dick Ibarra Grasso 1953:192.104.

El autor identifica un dibujo de un rectángulo negro con cama y lo lee $k a$ machikusqan, como en el caso precedente.

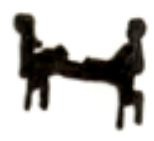

Dick Ibarra Grasso 1953:247:148

Según el comentario del autor, es un dibujo de una cama vista de lado, y leído kamachisqan, "por él mandado".

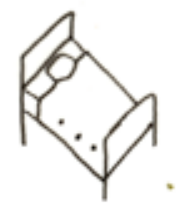

Juan Miranda M. 1988:32:04.2

Juan Miranda M. y sus catequistas usan un dibujo de una cama con almohadas y cubierta, que leen kama, "hasta".

Ejemplo 2: manta

Manta en español corresponde a un sufijo quechua, -manta, que significa "desde", "de".

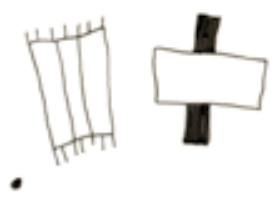

Walter Sánchez C. y Ramón Sanzetenea R. 2000:06:21 

"desde ahora".

El signo leído manta designa aquí el sufijo en la palabra kunanmanta,

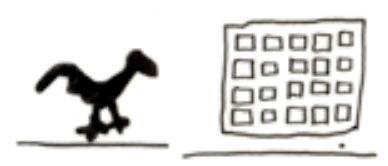

Dick Ibarra Grasso 1953:189:41-42

La secuencia de dos signos es leída yallinmanta, "más bien".

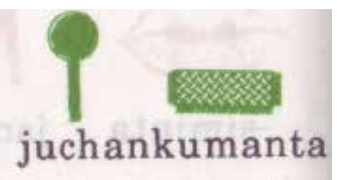

Juan Miranda M. 1988:32:18.

La secuencia se lee huchankumanta, "desde sus pecados, por sus pecados, de sus pecados".

El mismo signo - manta puede leerse de otra manera, pero fonéticamente cercana:

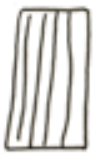

Walter Sánchez C. y Ramón Sanzetenea R. 2000:12:21.

Aquí el signo se lee amataq, "y no", lo que tiene sentido solamente porque lo sigue un signo leído como kachariwaykuchu, lo que junto significa "y no envíes contra nosotros". En la lectura ukhu pachaman, "al infierno", que corresponde a la secuencia de signos:

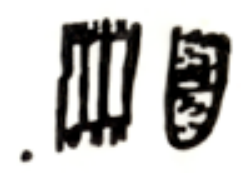

Walter Sánchez C. y Ramón Sanzetenea R. 2000:09:26,

el primer signo se lee $u k h u$ pacha, "infierno", y el segundo -man, sufijo que significa "a, hacia". En la lectura del signo manta ha quedado solamente la primera sílaba, man. En la secuencia de signos:

sajramantari

Juan Miranda M. 1988:18.03,

leída saqra-manta-ri, "y del demonio", los sufijos - manta-ri han sido escritos con los signos manta y tara. 
En los textos de Juan Miranda M. aparece también la lectura mana - no, en vez de manta:

Los ejemplos del signo manta demuestran que puede leerse de varias maneras, según el contexto: amataq, mana, man. Todas las lecturas de algún modo son similares a manta.

Jeroglíficos quechua-hispanos

Un ejemplo maravilloso de tales jeroglíficos, en los cuales se usa dibujos de palabras quechuas para anotar palabras españolas fonéticamente ajenas al quechua, son las palabras Jesús y Cristo.

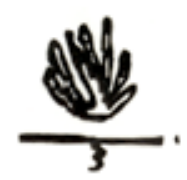

\section{Dick Ibarra Grasso 1953:190:133.}

El signo es un dibujo de la planta ichhu o hichhu, que aquí se lee Hisus, Jesús. El signo kiru, "diente", ya comentado más arriba como un signo que sirve también para escribir la palabra simi, "boca, palabra", se usa también como signo leído Cristo:

Dick Ibarra Grasso 1953:190.1.04.

Aparecen juntos en el texto de Juan Miranda M.:

\section{Jesucristoj}

Juan Miranda M. 1988:24.01,

en la secuencia Jesucristo, seguida del sufijo - $q$, antiguamente - $p$, “de”. Juan Miranda M. usó también un jeroglífico hispano-hispano:

Juan Miranda M. 1988:38:06,

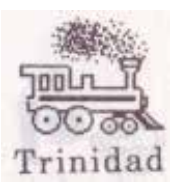


Un dibujo de un tren corresponde a la palabra Trinidad, que naturalmente abunda en un catecismo.

Signos compuestos

En los ejemplos ya discutidos aparecieron signos compuestos. Aquí discutiré solamente ejemplos que ilustran las reglas de construir un signo compuesto.

Ejemplo 1: Diosta muchíauspa

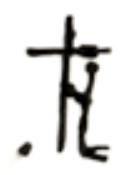

Walter Sánchez C. y Ramón Sanzetenea R. 2000:04:23.

El dibujo consta de una cruz y una persona arrodillada, cuyas manos tocan la cruz. El signo de la cruz se lee Dios, cruz o chakata. El dibujo de una persona arrodillada se lee confesa-, "confesarse". Los dos signos juntos forman una expresión que se lee Diosta muchia-, a la cual el lector, según el contexto, añade los sufijos necesarios: - $k u$-spa. La expresión leída significa "adorando a Dios". Los catequistas ya en el siglo dieciséis usaron el verbo mucha con el significado de ejecutar los gestos cristianos de adoración. Hasta hoy día el mismo verbo se refiere también a los gestos de adoración dirigida a los wamani, apu, awki, divinidades locales andinas.

Egemplo 2: Diosmanta mañapuwayku

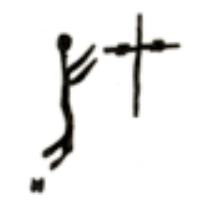

Walter Sánchez C. y Ramón Sanzetenea R. 2000:05:34.

El signo ha sido construido como el anterior, salvo que el arrodillado tiene las manos extendidas hacia la cruz pero no la toca. La expresión Diosmanta maña$p u$ - significa "pedir de Dios algo". El contexto hizo que el lector añadiera los sufijos necesarios: - wa-y-ku, lo que junto significa "pídelo o pedidlo de Dios para nosotros".

Ejemplo 3: taripaq hamunqa

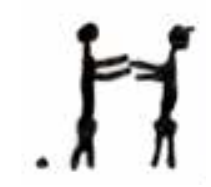

Walter Sánchez C. y Ramón Sanzetenea R. 2000:08.38. 
El signo consta de dos dibujitos, cada uno de una persona con las manos extendidas hacia la otra. Los dibujos de personas con las manos extendidas son muy frecuentes y aparecen en contextos muy diversificados. Aquí, los dos juntos llevan al lector a pensar en tari-, "encontrar". Más arriba di el ejemplo de tari-, "encontrar", representado por el dibujo del arbolito tara. En el caso de este tari el lector no lo lee simplemente tari, sino taripaq hamunqa, "vendrá a juzgar". En el contexto de una oración, el sufijo de tercera persona del futuro - nqa es obvio. Sin embargo, uno esperaría más bien una lectura como taripanqa, "juzgará", y no la que aparece: taripaq hamunqa.

Un signo casi igual lo publicó Dick Ibarra Grasso:

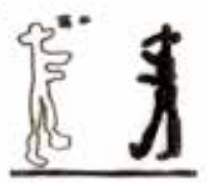

Dick Ibarra Grasso 1953:190:2:52-53,

pero con un significado diferente: chaymanta kayman, "desde allá hacia aquí". En este caso los personajes dibujados tienen colores diferentes: blanco y negro.

Ejemplo 4: kutisunaypaq

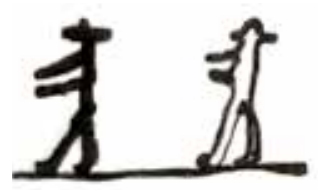

Dick Ibarra Grasso 1953:190:1:70-71.

El signo es casi igual al anterior, salvo que ambos personajes se dirigen hacia el mismo lado, siguiendo la dirección de la escritura. La raíz kuti, "volver, revertir, responder, vez, turno", recibió una secuencia de sufijos, su-na-y-paq, lo que crea el significado de: "para que yo vuelva a ti allä". En los textos coloniales tales formas no aparecen, sino qamta kutinaypaq. No está claro cómo el escribano de este signo y del anterior produjo aquí el significado de volver.

Ejemplo 5: tiyaykapurqa

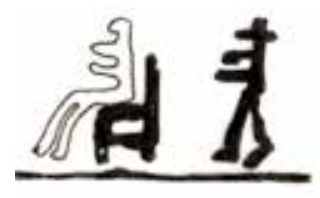

Dick Ibarra Grasso 1953:190:2:50-51.

La palabra tiya- significa estar sentado, sentarse, asentar, poblar. De hecho, el segundo signo dentro de la secuencia es un dibujito de una persona sentada en una silla, objeto no muy frecuente en las aldeas de habla quechua alrededor 
de 1950. El primer signo de la secuencia muestra a una persona que anda en dirección a la silla. Su función, no tan clara en casos anteriores, aquí se manifiesta mejor. Es un determinativo que indica movimiento o acción. Los dos signos juntos crean el significado de: tiya-yka-pu-, "sentarse allá definitivamente". El contexto de la oración sugiere que se sentó, de ahí el sufijo del pasado, -rqa.

Ejemplo 6: kusiyta qhawawayku

\section{A}

Dick Ibarra Grasso 1953:196:2:12-13.

Según las explicaciones añadidas por Dick Ibarra Grasso, el primer signo es un dibujo de una araña que cuelga en una telaraña desde un palito. Tal araña se llama en quechua kusi-kusi. La raíz kusi- significa feliz, alegre, buena suerte, y el donado de buena suerte en la vida cotidiana. El segundo signo es un dibujito de un hombre con las manos extendidas hacia delante. Parece un variante del determinativo de movimiento y acción. En este caso el hombrecito no va en la dirección de la escritura (en este caso de izquierda a derecha) sino en la contraria (es decir de derecha a izquierda). En cierto modo mira la araña o se acerca a ella. Juntos los dos signos crean la expresión: kusi-ta qhawa-, "mirar o cuidar buena suerte". El contexto le otorgó los sufijos necesarios: kusi-y-ta qhawa-wa-y-ku, "míranos la nuestra felicidad".

Ejemplo 7: qupuwayku

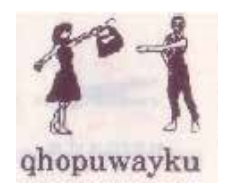

Juan Miranda M. 1988:17:04.

El signo consta de un dibujo de una mujer que entrega un paquete a un varón. Un varón igual o muy parecido aparece en otros contextos. Quizás sea un determinativo. $Q u$-, "dar, ofrecer", aquí lleva los sufijos - pu-wa-y-ku, lo que crea el significado de: "Dalo a nosotros definitivamente".

Los ejemplos sugieren que los signos compuestos tienen ciertos rasgos propios:

1. Conservan las oposiciones hanan - hurin, marcadas ya con color, ya con relleno, ya con sexo, ya con la dirección en la cual mira el personaje dibujado en comparación con la dirección del texto. Tal rasgo quizás aparece menos en los textos de Juan Miranda M., cuya forma es más moderna. 
2. Implican la necesidad de añadir sufijos que no se marcan, también entre las partes de la expresión. Me parece muy importante que el sufijo -ta, marcador de objeto directo, quizás no se marca jamás.

3. Indican la existencia de los determinativos, es decir signos que ayudan a entender otros signos.

\section{Determinativos}

En las escrituras bien conocidas, usadas durante milenios por miles y millones de personas, tales como la sumeria, acadia, egipcia, china o maya, los determinativos acompañan casi a cada signo, indicando una categoría semántica, sugiriendo la pronunciación, separando una palabra o un signo de otras palabras o signos. En los textos quechuas investigados los signos, que a falta de otro nombre bauticé con el de determinativos, cumplen otra función: le indican al lector una palabra que no ha sido escrita, y el lector debe suplirla según su entendimiento de otros signos. Es una función muy importante, ya que simplifica la notación e indica al lector que el signo corresponde a alguna palabra.

\section{Ejemplo 1}

En los textos publicados por Walter Sánchez C. y Ramón Sanzetena R. (2000) aparece un dibujo de una persona que anda con las manos hacia delante. En la secuencia:

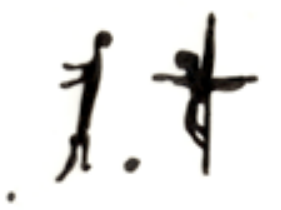

Walter Sánchez C. y Ramón Sanzetenea R. 2000:02.04,

que se lee: Jesucristo kawsarimusqan ("Jesucristo resucitado"), el dibujito significa kawsarimusqan, "resuscitado". En el texto no aparece ningún indicio de su fonética, ni de su significado. El único indicio es que debe haber aquí una palabra. En un signo compuesto:

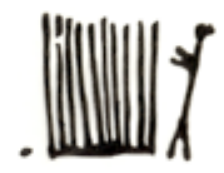

Walter Sánchez C. y Ramón Sanzetenea R. 2000:04.03,

que se lee: kay chunka ("estos diez"), el mismo signo indica la palabra kay, "este, esta, esto, estos, estas", e indica el numeral diez. Otra vez faltan referencias al sonido o significado, aparte de la posición delante del número diez que sigue. 
En otro signo complejo precede al signo cama o kama. El signo kama es leído kamachikuyninpi, "en el mandamiento". En este caso el mismo determinativo ha sido leído: ñawpaq, "primero":

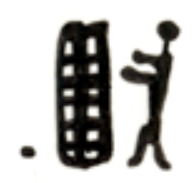

Walter Sánchez C. y Ramón Sanzetenea R. 2000:0.4.10,

lo cual crea la expresión leída: ñawpaq kamachikuyninpi, "en el primer mandamiento". Dentro de la secuencia:

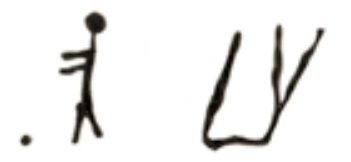

Walter Sánchez C. y Ramón Sanzetenea R. 2000:06.24-25,

mayukuna puririsan ("los ríos andan"), solamente indica la presencia de una palabra, en este caso puri, "ir, funcionar, andar". Cuando el lector leía correctamente el signo anterior: mayu ("río"), entonces tenía que darse cuenta de que aquí debe encontrarse una palabra que corresponde con mayu, "río". Falta cualquier indicación de sonido o significado. Lo único que queda es la información: aquí debe haber una palabra determinada por mayu.

En otra secuencia bien larga:

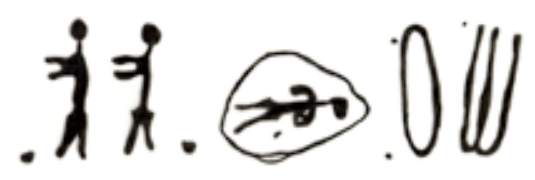

Walter Sánchez C. y Ramón Sanzetenea R. 2000:08.26-28,

kimza p’unchaw wañusqanmanta kawzarimurqa ("al tercer día desde su muerte de nuevo comenzó a vivir aquí"), el determinativo ha sido repetido dos veces en lugar de la palabra kawzarimurqa. El contexto de una oración bien conocida sugiere al lector la lectura de kawzari-, "revivir"; sin embargo, no hay ninguna sugerencia de fonética ni de significado, aparte de la repetición doble del signo.

En un Padrenuestro el signo aparece dos veces. He aquí toda la secuencia:

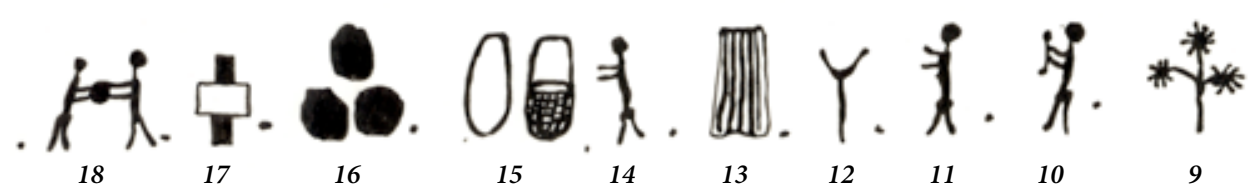

Walter Sánchez C. y Ramón Sanzetenea R. 2000:12.9-18. 
Cito el texto quechua en transcripción latina. En la cita, las sílabas que corresponden a los jeroglíficos las marco con mayúsculas, y lo añadido por el lector, con minúsculas. Cada palabra o grupo de palabras lleva el número del signo. Los dos determinativos van marcados en negrita:

9. MUNA-y-ni-yki 10. RURA-sqa ka-chu-n, 11. imayna-chus 12. HANAQ pacha-pipis 13. kay PACHA-pi-pis 14. hina-lla-taq-mi. 15. ZAPA P'UNCHAW 16. T'ANTAy-ku-ta 17. KUNA-n 18. QU-pu-wa-y-ku.

lo que en castellano corresponde a la siguiente secuencia, que conserva el orden sintáctico quechua:

9. VOLUntad tuya 10. HECHa sea 11. como 12. en ALTO mundo también 13. este MUNDO también 14. y así nomás 15. CADA DÍA 16. PAN nuestro 17. AHORa 18. DAnos definitivamente

Ambas apariciones del determinativo están marcadas en negrita también en la traducción. En ambos casos falta cualquier indicación del significado o del sonido de la palabra. Lo importante es marcar la presencia de una palabra en un texto de todos modos ya muy bien conocido.

No sé predecir cuando aparece el signo de signo, es decir el determinativo, ni con qué significado. En dos versiones del Padrenuestro, escritas por dos escribanos diferentes en dos comarcas diferentes, se encuentra la misma expresión: muchasqa kachun, "alabado sea (Tu nombre)", compuesta de la palabra kachun, "sea", y de la palabra muchiasqa, "adorado" o "besado". En el siglo dieciséis y hasta ahora la raíz muchia se refiere a gestos rituales dirigidos hacia los dioses y también, pero con sufijos diferentes, significa besar. Así, en el Padrenuestro de Cochabamba se encuentra el signo siguiente:

.

Walter Sánchez C. y Ramón Sanzetenea R. 2000:12.05,

que sin duda alude a la raíz mucha; entonces: muchasqa kachun, "adorado sea".

En otro Padrenuestro publicado por Dick Ibarra Grasso la misma expresión contiene dos signos:

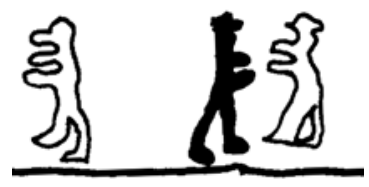


El primero son dos determinativos, uno blanco y otro negro, dirigidos uno hacia el otro. El segundo es kachun, escrito con un jeroglífico, que según las explicaciones de Dick Ibarra Grasso (1953:172) representa a una persona que khachun, "come una fruta dura, inmadura, de tal modo que se oye el sonido cuando la mastica". Entonces la palabra kachun, "sea", omitida en la versión anterior, aquí ha sido anotada. Pero "besar" acabó sustituido por dos determinativos con contraste de color y de dos personas encaradas, como se debe durante el besar. Nada recuerda la fonética o el significado. Lo único recordado es la participación de dos personas, que no tienen nada que ver con la adoración a Dios.

Otros casos de determinativo que he observado y entendido en los textos publicados por Dick Ibarra Grasso repiten los usos descritos arriba con ejemplos cochabambinos. Sin embargo, merece atención especial el uso del determinativo en la secuencia siguiente:

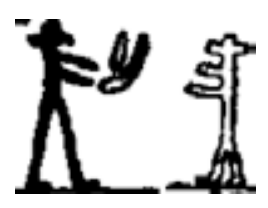

Dick Ibarra Grasso 1953:190.1.56-57,

que se lee: K'anchayniykiwan k’anchaykuwayku, "con tu luz alúmbranos". El significado de la raíz k'ancha ("luz, iluminar") está anotado con un dibujito de una persona con llamas o velas en las manos. El signo que sigue es un determinativo, esta vez blanco, alumbrado frente al portador de la luz, completamente negro. La lectura kanchaykuwayku ("alumbra nos") proviene del contexto y de llamar la atención sobre el signo precedente dirigiendo el determinativo en contra de la dirección de la escritura.

Un determinativo parecido, con los significados chay, "ese, esa, eso", y ñi/ni, "decir, significar", aparece en el librito de Juan Miranda M.:

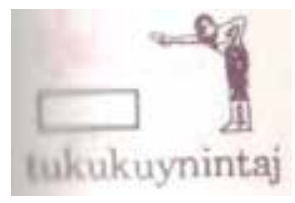

Juan Miranda M. 1988:27:17

tukukuynintaq -

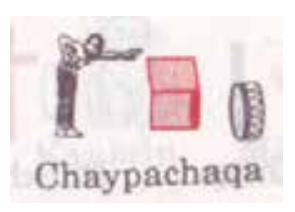

Juan Miranda M. 1988:36:16 chay pachaqa.

En el primer ejemplo el determinativo es a la vez un jeroglífico, ya que aprovecha la homofonía entre ñin o nin, "él dice", y la secuencia de sufijos -ni-n, "suyo de él/ ella/ellos/ellas". 
En los textos aparecen más signos que pueden ser determinativos. Sin embargo, no sé definir su función de manera suficientemente clara, tal como en los ejemplos ya discutidos. Me parece que los ejemplos discutidos indican ciertos rasgos de los determinativos:

1. pueden sustituir un signo;

2. su significado depende de la posición frente a la dirección de la escritura, que o concuerda con ella, o se le contrapone;

3. entran en contrastes marcados con lo blanco y lo negro;

4. quizás también participan en oposiciones entre lo femenino y lo masculino. El signo compuesto $q u$, "dar", incluye un dibujo de una mujer donante y de un varón receptor:

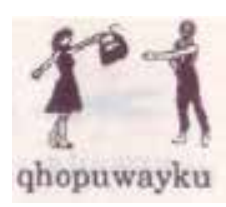

Juan Miranda M. 1988:17:04.

\section{Resultados del análisis sincrónico de los signos}

1. Los signos tienen significado solamente dentro de una secuencia. Por sí solos y separados son ilegibles. Su significado se construye con los componentes del mundo y de la cultura de sus autores, siempre en secuencias. Por eso la frontera entre un signo compuesto o una secuencia de signos resultó poco clara y poco útil. Quizás se podrá obtener mejores resultados analizando los componentes de los signos compuestos como signos separados e individuales.

2. Durante la construcción de los significados de una secuencia de signos valen e influyen las categorías clasificatorias divulgadas en los Andes centrales desde tiempos inmemoriales. Claramente se dan clasificaciones binarias llamadas por los andinistas oposición hanan-hurin.

3. En la notación se aprovechan jeroglíficos construidos dentro de una sola lengua, el quechua, y otros que aprovechan las palabras castellanas. No he buscado jeroglíficos construidos con palabras aymaras y quechuas. En Qulla Suyu, igual que en el Cuzco del siglo dieciséis, los fondos léxicos creados dentro de la liga lingüística centroandina incluyen hasta el 40 o $50 \%$ de las raíces. Entonces por lo menos una parte de los signos y de sus secuencias puede ser común, más aún cuando la notación omite los sufijos.

4. Los sufijos pueden anotarse y a veces se anotan. Como los textos escritos son textos para aprenderlos de memoria, entonces los catequistas y los maestros de este modo de escribir (que son los mismos) no necesitan una notación completa que anote todas las palabras y sus formas. En definitiva, el maestro conoce el texto 
de memoria y esto lo diferencia del alumno. Posiblemente si uno pidiese a un escribano que escribiese un texto que no fuese conocido de memoria, la notación de los componentes sería más detallada.

Dick Ibarra Grasso (1953:196.2) pidió a un escribano de la escuela de Yapusiri, en la provincia de San Lucas, que escribiera una oración dirigida a Iqiqu, o Hiqiqu, dios de la abundancia muy adorado en todo Qulla Suyu y Cuzco. He aquí el texto:

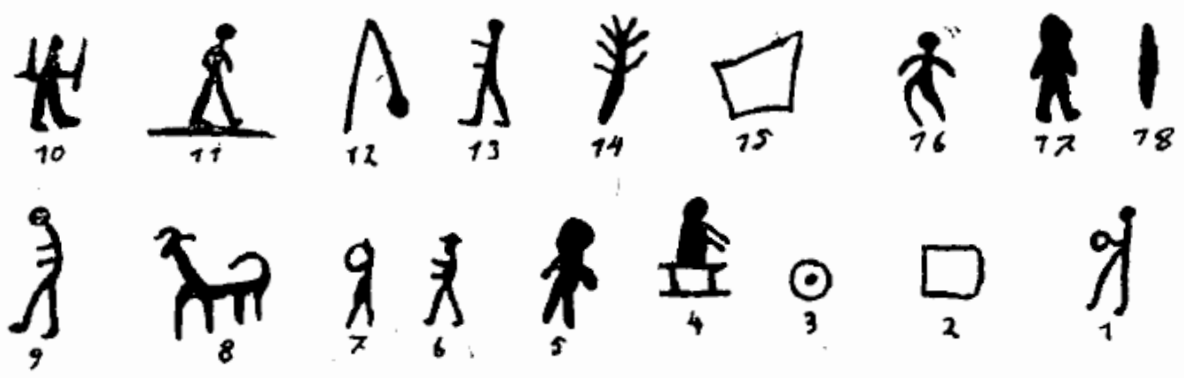

Verso escrito en prueba. Escuela de Yapusiri. San Lucas.

Contiene el canto:

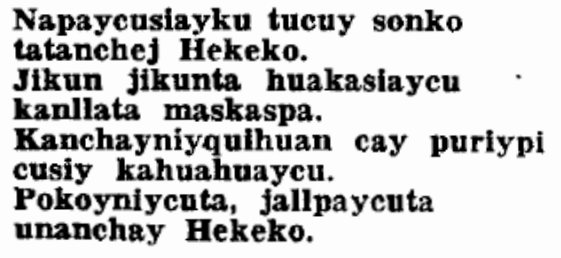

Napaycusiayku tucuy sonko tatanchej Hekeko.

Jikun jikunta huakasiaycu kanllata maskaspa.

Kanchayniyquihuan cay puriypi Pokoyniycuta, jallpaycuta unanchay Hekeko.
1, hombre que saluda; 2, tocuyo, fonema; 3, corazón; 4, Señor o altísimo; 5, Hekeko, hombre diminuto $y$ cabezón; deidad india; 6 , amargado muy amargado, hombre amargado; 7, "llorando"; hombre llorando; 8, perro (kan, tu); 9, buscando, hombre buscando; 10, "con tu luz", hombre con velas en las manos; 11, "hombre sobre el camino"; 12, araña colgando de un palo, alegría; 13, hombre mirando a la araña; 14 , producto, fruto; 15 , terreno de cultivo; 16 , hombre meditando o pensando; 17, Hekeko. 18, punto final.

En la tabla de abajo presento la relación entre el texto, su lectura y su traducción:

( $\mathrm{N}^{\circ}$ - número del signo en la secuencia,

+1 - palabra(s) añadida(s) por el lector delante del signo, en su forma cuzqueña SIGNO - la raíz leída, en su forma cuzqueña

+2 sufijos y palabras añadidas por el lector después del SIGNO, en su forma cuzqueña

Lectura - la forma fonémica anotada por Dick Ibarra Grasso (Traducción) 


\begin{tabular}{|c|c|c|c|c|c|}
\hline No & +1 & SIGNO & +2 & lectura & Traducción \\
\hline 01 & & $N A P A$ & $\begin{array}{c}-y k u-c h k a- \\
y-k u\end{array}$ & Napaykusyayku & $\begin{array}{l}\text { Te estamos } \\
\text { saludando }\end{array}$ \\
\hline 02 & & TUKU & $-y$ & tukuy & todo \\
\hline 03 & & SUNQU & & sunqu. & corazón. \\
\hline 04 & & TATA & -nchik & ¡Tatanchik & Nuestro Padre \\
\hline 05 & & HIQIQU & & Hiqiqu! & Iqiqu! \\
\hline 06 & & determinativo & & Hik'un-hik'unta & con hipo \\
\hline 07 & & WAQA & $-c h k a-y-k u$ & waqasyayku & estamos llorando \\
\hline 08 & & $Q A N$ & -lla-ta & qanllata & a ti solo \\
\hline 09 & & MAZKHA & $-s p a$ & maskhaspa. & buscando \\
\hline 10 & & K'ANCHA & $-y-n i-y k i-w a n$ & K'anchayniykiwan & Con tu luz \\
\hline 11 & kay & PURI & $-y-p i$ & kay puriypi & en este viaje \\
\hline 12 & & KUSI & $-y$ & kusiy & nuestra felicidad \\
\hline 13 & & determinativo & & qhawawayku. & míranosla \\
\hline 14 & & PUQU & $-y-n i-y k u-t a$ & Puquyniykuta & $\begin{array}{l}\text { A nuestra } \\
\text { cosecha }\end{array}$ \\
\hline 15 & & HALLP'A & $-y-k u-t a$ & hallp'aykuta & a nuestra tierra \\
\hline 16 & & UNANCHA & $-y$ & unanchay. & aconséjale \\
\hline 17 & & HIQIQU & & ¡Hiqiqu! & Hiqiqu! \\
\hline 18 & & AMEN & & Amen & Amén \\
\hline
\end{tabular}

Sin embargo, el ejemplo no satisface las esperanzas. Los determinativos indican palabras sin anotar, y los sufijos fueron añadidos por el lector.

5. Los signos son convencionales, establecidos por el uso entre escribanos y lectores, con costumbres y convenios diferentes en cada comarca.

6. Parece que el sistema de signos es un sistema abierto, es decir que cada escribano puede crear y añadir signos nuevos. 


\section{Fonémica y gramática de los textos escritos}

La fonémica de la notación en los jeroglíficos y asociaciones no corresponde con el quechua parcialmente. El esquema canónico de una sílaba quechua es $\mathrm{CV}(\mathrm{C})^{2}$, fuera de la primera sílaba de una palabra, donde es posible también $(\mathrm{C})$ $\mathrm{V}(\mathrm{C})$. Bajo la influencia castellana aparecen préstamos del castellano con dos consonantes al comienzo, como el jeroglífico trin (tren) para escribir Trinidad. En las inscripciones estudiadas normalmente se escriben las raíces solas, que en quechua, con pocas excepciones, son bisilábicas, con la segunda sílaba abierta, como en la oración a Hiqiqu, citada arriba. El primero de los signos es:

$$
\text { व }
$$

napa, "saludar". El dibujo representa a un hombre con un sombrero en la mano. Tal signo por supuesto es posible solamente después de la conquista española, cuando se comenzó a mostrar el respeto a una persona o a Dios quitándose el sombrero. Un gesto así no se practicaba en la época inca. El mismo signo podría usarse para escribir cualquier secuencia napa, como en runakunapaq. Sin embargo, no he encontrado tal caso.

En el Padrenuestro publicado por Dick Ibarra Grasso se encuentra un caso muy ilustrativo del uso del signo kiru, "diente", dentro de la secuencia siguiente:

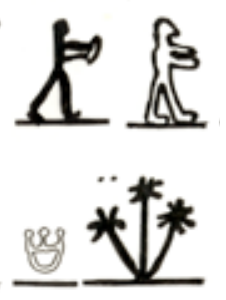

Dick Ibarra Grasso 1953: 189.

La secuencia está dividida en dos partes, la primera en un renglón de abajo, escrita de derecha a izquierda, y la segunda en el renglón de arriba escrita de izquierda a derecha. Su lectura es la siguiente:

\section{MUNA-y-ni-y 12. KIRU 13. RUWA-sqa-taq 14. KACHU-n 11. VOLuntad tu 12. YA 13. HECHa 14. SEa}

He comentado más arriba todos los signos que componen la secuencia. Es muy importante el hecho de que el signo 12. kiru pierde su segunda sílaba $r u$, y el signo siguiente, 13. ruwa, comienza por la misma sílaba ru perdida por el signo 12. Parece un medio que debe facilitar la lectura, es decir cumple la función de un determina${ }^{2} \mathrm{C}$ - cualquier consonante, $\mathrm{V}$ - cualquier vocal. 
tivo. En consecuencia la palabra munayniyki ha sido escrita como MUNA-y-ni-yKI. Los sufijos colocados detrás de MUNA y antes de la sílaba KI no han sido escritos ni marcados. El lector los suplió. Hasta entonces no tuvo que sustituir un fonema por otro, como en el signo LLUQHA o NUQA, ya comentado. En este último caso el fonema $l l$ fue sustituido por $\tilde{n}$, y el fonema $q$ por el de $q h$. En el último signo de la secuencia 14. KHACHU, "masticar una fruta no madura", leído kachun, "sea", el fonema $k h$ ha sido sustituido con el fonema $k$ durante la lectura.

En el quechua de Qulla Suyu la diferencia entre tales fonemas es por lo menos tan significativa como en castellano la diferencia entre $p$ y $b$. Miremos por ejemplo la diferencia entre perro y berro. Un ejemplo en quechua son las palabras tanta, "reunirse", t'anta, "pan", y thanta, "lo gastado, trapo", que comienzan con fonemas diferentes. La notación basada en jeroglíficos quechua-quechua o hispanoquechuas pasa por alto tales diferencias de fonemas. En las lenguas usadas y conocidas en Qulla Suyu hoy día, con excepción del castellano, la oposición entre fonemas simples, glotalizados y aspirados es general. Uno esperaría que tal diferenciación existiese en la notación jeroglífica, pero no existe.

En quechua y en aymara -en todos sus dialectos- la derivación y las funciones de una palabra dentro de la oración se marcan siempre y solamente con sufijos. Los prefijos no existen. En los ejemplos comentados aquí los sufijos se marcan raras veces. En la oración al Hiqiqu, citada arriba, no está marcado ni uno solo. Veamos ejemplos de notación de sufijos:

\section{1. wawaykiri}

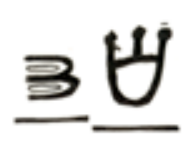

Dick Ibarra Grasso 1953:190:1:16-17.

El primer signo es un signo establecido por convenio. El dibujo representa dos niños de pecho, wawa. Como todo el texto es leído en singular, entonces en este caso el signo es leído wawa y no por ejemplo wawa-wawa, o wawa-kuna, aunque la lectura en plural también es posible. Junto con el signo siguiente KIRI, ha sido leído: WAWA-yKI-RI, "y tus niños, y tus wawas". El escribano marcó una parte del sufijo $y k i$, "tuyo"-, y el sufijo -ri, "tema nuevo de la conversación"- con un solo signo KIRI.

\section{2. kunanmantari}

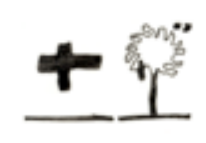

Dick Ibarra Grasso 1953:190:1:58-59. 


\section{Jan Szemiński}

El primer signo son piedras de moler. Este tipo de batán se llama qhuna. En el contexto de la oración, el signo QHUNA fue leído kuna-n, con la sustitución del fonema $q h$ por el fonema $k$. El segundo signo es TARA, ya comentado. Sin embargo el lector de la secuencia la leyó como KUNA-n-manTA-ri. Una parte del sufijo - manta, la sílaba man, fue añadida por el lector. La segunda sílaba de TARA fue convertida en el sufijo - ri, "tema nuevo".

El mismo signo QHUNA se usa también como signo del sufijo -kuna, plural. En textos mas recientes fue sustituido por el jeroglífico hispano-quechua CUNA, leído en quechua no como cuna para niños, sino como -kuna, sufijo del plural, como en el ejemplo siguiente:

\section{3. hanaq pachakunatawanpis}

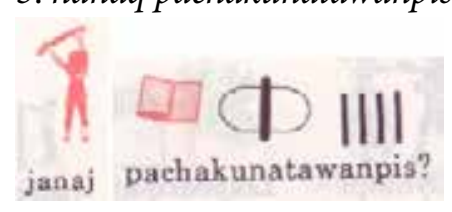

Juan Miranda M. 1988:07-08.

El primer signo $H A N A Q$, "en lo alto", sirve de adjetivo que precede al signo P’ACHA, "una tela, ropa". Juntos los dos signos se leen hanaq pacha, "el cielo, el mundo de arriba" o "la gloria". Los sigue el signo CUNA, es decir -kuna-, plural. Así se recibe hanaq pachakuna, "los cielos". El último signo de la secuencia es TAWA, "cuatro", que aquí se lee como una secuencia de dos sufijos, ta-wan. El primero de ellos denota objeto directo y el segundo significa " $y$ ". La secuencia es parte de una frase que dice que Dios había creado la tierra y los cielos. El último sufijo - pis, "también", no fue marcado por ningún signo, sino suplido por el lector

\section{4. aynintaq}

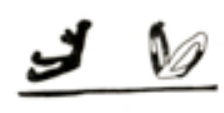

Dick Ibarra Grasso 1953:192:016-017.

Según una explicación de Dick Ibarra Grasso (1953:182), el primer signo es un dibujo de una persona que sufre y se queja diciendo ay. El segundo signo es RINRI o NINRI, “orejas". Juntos se leen: AY-NI-N-taq, e intercambian el ayni. Del signo NIRI ha quedado solamente la silaba nin, y el sufijo -taq fue suplido por el lector.

\section{5. kanki}

Dick Ibarra Grasso 1953:192:025. 
Según Dick Ibarra Grasso es el dibujo de un asado dentro de una olla. El asado en quechua se llama kanka. Aquí el signo se lee KA-NKi, "eres, serás”. La segunda sílaba $k a$ ha sido cambiada por $k i$.

\section{Santa Cruzpa unanchanrayku awqaykunamanta qhispichiwayku, ¡Dios!}

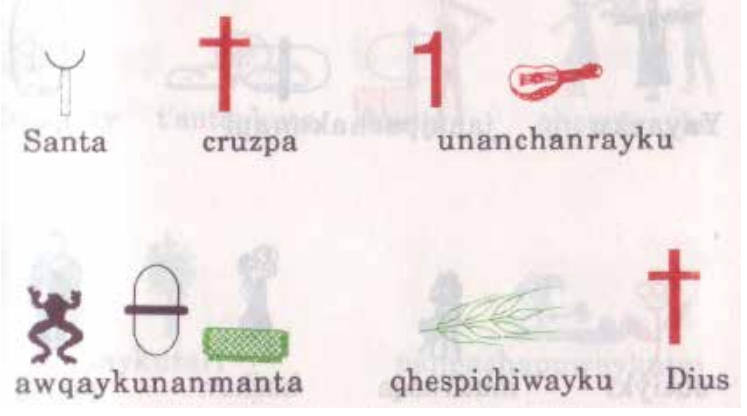

Juan Miranda M. 1988:15.

En la traducción sigo el orden quechua de las palabras: De Santa Cruz por su signo de nuestros enemigos sálvanos ¡Dios!

En la oración se encuentran dos palabras con sufijos marcados.

Unanchanrayku ("a causa de su signo") está marcado con la cifra UNA. El lector añadió la $n$. Después de $U N A$, el escribano añadió un jeroglífico dibujando un CHARANGO. Sin embargo, el signo no se lee en este caso CHARANGO, sino CHA-N$R A Y K U$. La sílaba cha de charango se convierte en la sílaba chan, dentro de la palabra unancha-n. Las sílabas rango son convertidas en el sufijo rayku, "a causa de".

Awqaykunanmanta se compone de un signo del sapo, hamp'atu, leído en este caso como awqa, "enemigo". El lector le añadió el sufijo - $y$, "mío". Los dos signos siguientes han sido comentados más arriba: el primero es CUNA o KUNA, plural, y el segundo MANTA - o el sufijo manta, "desde". Toda la palabra se compone entonces de partes anotadas con jeroglíficos y de las añadidas por el lector: $A W Q A$ $y$-KUNA-n-MANTA. No han sido escritos solamente dos sufijos: $-y,-n$.

En comparación, la palabra siguiente, qhispichiwayku, "sálvanos", es un jeroglífico quechua-quechua, basado en la similitud de sonidos de dos palabras: q'ispi, "espiga, espigar", y qispi o qhispi, "estar a salvo, sin peligro". En este caso ni un solo sufijo ha sido escrito o marcado.

Los ejemplos sugieren que se puede escribir los sufijos, pero no se los suele escribir. En textos más cuidados se anota preferiblemente sufijos o secuencias de sufijos que suenan como una palabra en quechua o en castellano. No he encontrado ni un solo caso de anotar dos consonantes de un sufijo, aunque existen sufijos que comienzan con dos consonantes.

También en la notación de los sufijos la última sílaba de un signo puede omitirse o sustituirse por otra. A veces en una secuencia de signos la última sílaba del primer signo se omite también cuando el siguiente signo comienza por la sílaba omitida. 
Al considerar la presencia o la ausencia de los sufijos, debemos preguntar: ¿qué es lo que permite omitirlos? En quechua o aymara una secuencia de palabras sin sufijos no se entiende, del mismo modo que en castellano una secuencia de palabras sin sus sufijos, artículos y preposiciones. Entonces una persona que no conoce el texto, no lo puede leer. El conocimiento previo del texto y de sus fórmulas es la condición primaria para poder leerlo correctamente. Todos los textos escritos con jeroglíficos: católicos, andinos (como la oración dirigida al Hiqiqu), o cívico-patrióticos (como una traducción del himno boliviano al quechua escrita con jeroglíficos), son textos de la fe, consagrados por la sociedad. Su consagración fortalece su conocimiento, y su conocimiento a la vez disminuye la necesidad de anotar los sufijos.

En quechua la raíz no cambia. Todos los sufijos conocidos funcionan sin excepciones y tienen sus lugares fijos en las secuencias de sufijos. Por ejemplo, cualquier objeto directo de cualquier verbo debe llevar el sufijo - ta. Entonces, si el verbo es veo, entonces veo: warmi-ta - "a una mujer"; chakra-ta - "una chacra"; misi-ta - "un gato"; churin-ta - "a su hijo". Igualmente, si te pedimos algo para nosotros, todos los verbos recibirán la misma secuencia de sufijos: qupu-wa-y-ku - "danos"; qhispichi-wa-y-ku - "sálvanos". Añadir sufijos de posesión o de persona es automático y obligatorio. Entonces, si el lector logra identificar al destinatario del texto (Dios, Hiqiqu, Patria, etc.), sabrá qué sufijos añadir.

Sin embargo, las diferencias de lectura son inevitables. A veces las lecturas de oraciones católicas difieren en algunas palabras, como en el ejemplo de yupa y hunt'a ya discutido. En tales casos sospecho la presencia de errores de lectura.

\section{La diacronía de los signos}

Todos los textos hoy conocidos provienen de los siglos diecinueve y veinte. Todas las lecturas que he visto contienen jeroglíficos hispano-quechuas, basados en palabras españolas. La descripción de las "ruedas de pedrezuelas" hecha por Joseph de Acosta, ya citada, indica la existencia y divulgación de tales modos de anotar informaciones ya antes de 1590. La mención dejada por el Inca Garcilaso de la Vega, también citada, sugiere que tal forma de escribir fue anterior a la conquista española de los Andes. ¿Es posible descubrir el origen y desarrollo de esta forma de notación a través de la crítica interna de los textos de los siglos diecinueve y veinte?

La teoría más divulgada y más aceptada, que podríamos llamar oficial, supone que la notación jeroglífica de Qulla Suyu fue creada y divulgada por frailes franciscanos, influidos por su experiencia mexicana a partir del comienzo de la misión franciscana en los Andes, es decir teóricamente desde 1533 y realmente desde 1542. La versión más actual de la teoría misionera la formularon cautelosamente William P. Mitchell y Barbara H. Jaye en su artículo: "Pictographs in the Andes: The Huntington Free Library Quechua Catechism”, publicado en Latin American Indian Literatures Journal, vol. 12, n. 1, 1996, páginas 1-42. El análisis de un manuscrito del 
siglo diecinueve, guardado en la Biblioteca Huntington, está acompañado por una revisión muy detallada y muy racional de las teorías sobre el origen de los pictogramas, y un repaso a las publicaciones sobre el tema. El artículo contiene también una lista de los manuscritos pictográficos conocidos en diferentes colecciones y publicaciones. Sus conclusiones son las siguientes:

1. La teoría de Dick Ibarra Grasso sobre el origen precolonial de los pictogramas parece ser falsa;

2. La teoría de la inspiración mexicana de la notación adolece de falta de evidencias;

3. Como los ejemplos de los pictogramas hoy conocidos provienen todos de los siglos diecinueve y veinte, entonces su similitud con los pictogramas mexicanos del siglo dieciséis se origina en la misma idea de presentar y enseñar oraciones y catecismo con dibujos.

Propongo otro modo de análisis. Para discutir el origen de los pictogramas no se puede usar jeroglíficos hispano-quechuas ni quechua-hispanos, ya que obviamente son coloniales y post-coloniales. En el caso del signo de la locomotora, llamado TRIN y leído Trinidad, la datación del signo tiene que ser posterior a la construcción de ferrocarriles en los Andes. De la misma manera el signo NAPA, "saludar", dibujado como un hombre con un sombrero en la mano, tiene que ser una consecuencia de la introducción del modo español de saludar. Entonces la búsqueda tiene que limitarse a jeroglíficos que correspondan a ideas indudablemente andinas. Está claro que puede haber ideas comunes, desarrolladas en Europa y en los Andes independientemente. Por ejemplo, el signo WANUUCHI, "matar, causar muerte, asesinar", tanto en los Andes como en Europa puede ser un dibujo como una persona que con un cuchillo ataca a otra persona, que cae o ya está en el suelo.

Hay que buscar entonces ideas que no puedan ser compartidas, no contengan jeroglíficos hispano-quechuas, ni incluyan cosas o costumbres de origen europeo. $\mathrm{He}$ aquí ejemplos de signos que a mi parecer cumplen con el requisito:

1. tuta p’unchaw, "noche y día, veinticuatro horas".

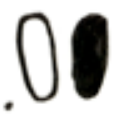

Walter Sánchez C. y Ramón Sanzetenea R. 2000:01.07

Walter Sánchez C. y Ramón Sanzetenea R. 2000:11.39 
Las veinticuatro horas comienzan en los Andes al caer la noche, y no a media noche como en general en las Españas y en toda Europa. Dentro de una tradición andina tal signo puede ser inventado por cualquier tradicionalista andino, pero no por un cura.

1. ukhu pacha, "el mundo de dentro, el infierno"

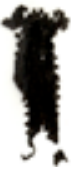

Dick Ibarra Grasso 1953:247:089.

El sapo es el símbolo de la Pacha Mama, Madre Tierra, o Señora del Espacio-Tiempo. Es una tradición indudablemente andina. El dibujo no es muy claro. Además conozco solo un caso de su ocurrencia. Hay que tratarlo entonces solamente como indicio, sugerencia de cierta posibilidad.

\section{3. muyuq wayra}

tatanchik Walter Sánchez C. y Ramón Sanzetenea R. 2000:02.11

tukuy wayra Walter Sánchez C. y Ramón Sanzetenea R. 2000: 06.08

El primer caso del signo, que he llamado muyuq wayra, se refiere a Jesucristo y se lee tatanchik, "nuestro padre" o "nuestro señor". En el segundo caso se lee tukuy wayra, "todo viento, cada viento", en un contexto de descripción de la omnipotencia de Dios.

En el drama "Ataw wallpap p’uchukakuyninpa wankan" aparece la expresión: muyuq wayra. Waylla Wisa, el gran sacerdote y primo de Ataw Wallpa Inqa, enviado por el Inka para hablar con los españoles, les dice: ¡Awqa zunkha puka runá! ¿Ima muyuq wayrataq hallp’aykuman llaqtaykuman apamusurqanki? (Husson 2001:versos 418-421) “¡Bárbaros de barba roja! ¿Qué remolino del viento os ha traído a nuestra tierra y a nuestro país?" Muyuq wayra, "remolino del viento", conecta este mundo donde vivimos con el mundo de abajo y de dentro. Según los 
andinos, los españoles y generalmente los europeos vienen del mundo de abajo, de $u k h u$ pacha. Entonces, leer el título de Jesús como tatanchik-nuestro padre o nuestro señor- es un acto de sustituir o reinterpretar el signo. En el Tawantin Suyu, Jesús aparece saliendo desde la profundidad de una roca, desde un pozo, o desde la tierra, y siempre es nombrado como tatanchik o taytanchik. En el segundo caso el lector omitió la palabra muyuq, "que da vueltas", y leyó solamente la palabra wayra, "viento, aire". No hay aquí ninguna contaminación con el signo del sol, ya que el sol es representado con el dibujo de una rueda, y cuando lo dibujan con rayos, los rayos son siempre rectos.

El signo muyuq wayra puede ser muy antiguo, e indudablemente fue creado por una persona versada en las tradiciones andinas, y no por un cura, ya que comúnmente muyuq wayra ("un remolino del viento") se interpreta como mala señal. Su presencia en los textos de catequesis y en referencia a Jesús no puede provenir de un cura.

4. qhispi

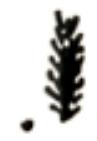

Walter Sánchez C. y Ramón Sanzetenea R. 2000:10:25

qhispichinawanchik, "nuestra salvación futura",

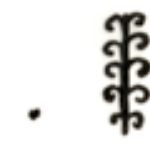

Walter Sánchez C. y Ramón Sanzetenea R. 2000:12:28

qhispichiwayku, "sálvanos",

Dick Ibarra Grasso 1953:189:43

qhispichiwayku, "sálvanos",

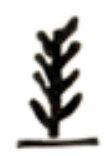

Dick Ibarra Grasso 1953:190:1:10

qhispichiqiy, "mi o nuestro salvador respetable", 


\section{qhespichiwayku}

qhispichiwayku, "sálvanos".

Todos los ejemplos repiten el mismo jeroglífico quechua-quechua, entre la palabra q'ispi, "espiga, espigar", y la palabra qhispi o qispi, "estar a salvo, salvar", que ya he analizado más arriba. El fonema $q$ ' ha sido sustituido por $q$ h o $q$, según el dialecto.

Un jeroglífico muy similar, basado en cambiar una consonante por otra, entre $c h, c h$ ' o $c h$, se encuentra en el escudo propio de los incas dibujado por Don Phelipe Guaman Poma de Ayala, en la página 83 de su obra:

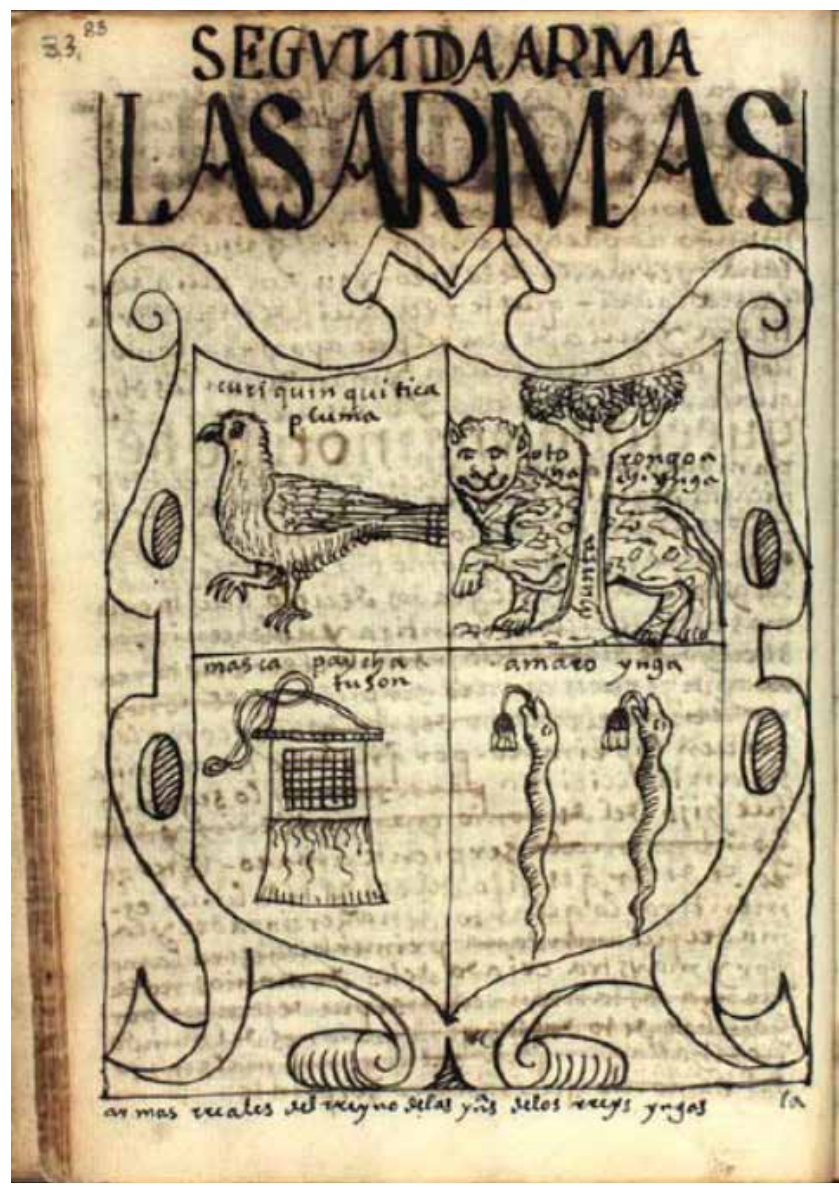

Figura 4. En el escudo propio de los incas dibujado por Don Phelipe Guaman Poma de Ayala: http://www.kb.dk/permalink/2006/poma/83/es/text/?open=id3082991 
Es un escudo aparentemente español. En su campo superior izquierdo, según las reglas de la heráldica, se encuentra una palmera chunta y detrás de ella un jaguar. Las inscripciones en el campo identifican el jaguar como chunta otorongo achachi ynga según la notación del autor. Analizando el escudo demostré que la palmera chunta significa aquí la palabra chiunta, "guerrero", presente en los vocabularios aymaras (Szemiński 1992). La relación entre chunta, "palmera” y ch’unta, "guerrero", es parecida a la relación entre qispi, "seguro, a salvo", y q'ispi, "espiga, espigar". Las palabras emparejadas difieren una de otra por la presencia o ausencia de la glotalización. Para fechar los jeroglíficos es muy importante que el jeroglífico chunta, chiunta aparezca en un escudo que describe a dos jefes de una organización incaica anterior a la construcción de la capital en Cuzco. Si bien el dibujo proviene de alrededor de 1615, cuenta sin embargo hechos de una tradición oral, que pudieron corresponder a hechos históricos que tuvieron lugar en Paqariq Tampu hacia 1200 , donde residieron los jefes incas de aquel tiempo.

\section{5. tata}

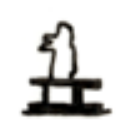

Dick Ibarra Grasso 1953:191:3:03

tatay, "mi padre, mi señor"

Dick Ibarra Grasso 1953:191:3:11

tatanchik, "nuestro padre, nuestro señor"

Dick Ibarra Grasso 1953:191:3:20

tatanchik, "nuestro padre, nuestro señor"

tatanchik, "nuestro padre, nuestro señor" 


\section{施}

Tata

Juan Miranda M. 1988:35:18

tata, "padre, señor"

El signo tata, "padre, señor", a mi parecer es un dibujo de una momia sentada en unas andas, muy parecida a las momias dibujadas por Don Phelipe Guaman Poma de Ayala:
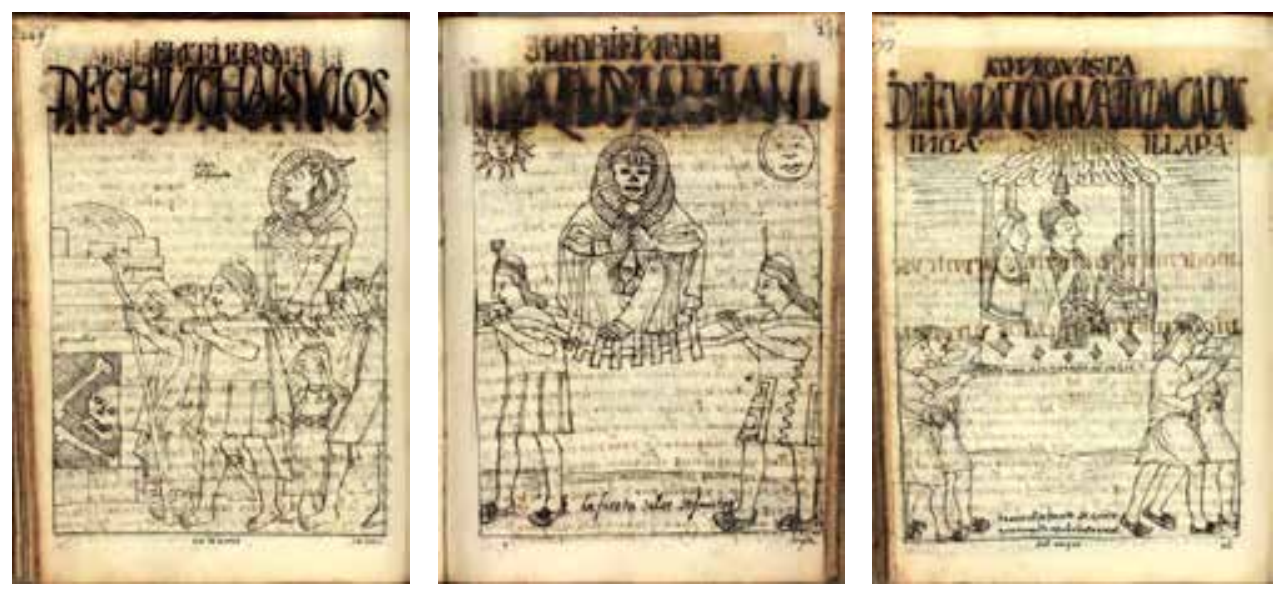

Figura 5. Las momias dibujadas por Don Phelipe Guaman Poma de Ayala:

izquierda: http://www.kb.dk/permalink/2006/poma/291/es/text/?open=id3087246 centro: http://www.kb.dk/permalink/2006/poma/258/es/text/?open=id3086896 derecha: http://www.kb.dk/permalink/2006/poma/379/es/text/?open=id3087886

Sus dibujos son muy importantes. Las momias sentadas en andas dejaron de viajar por los Andes en el siglo dieciséis. Algo más duraron los viajes de los grandes señores, andinos y españoles, que todavía a comienzos del siglo diecisiete solían viajar en andas, pero también dejaron de hacerlo en el siglo diecisiete. Desde aquel entonces los únicos que viajan en andas hasta hoy día son los santos durante las procesiones. Se puede dudar si el signo corresponde a una momia o a un santo. Sin embargo, el hecho de que no se trata de un santo es la lectura básica del signo tata y del signo mama, discutido a continuación.

El vocabulario más antiguo quechua español contiene la siguiente definición: Tayta, padre de niños tata, o yayanc (Fray Domingo de Santo Thomas 1560:98v).

Esta información acaba con la antigua discusión de si las palabras tata y tayta 
son un hispanismo o son andinas. Tata es una palabra andina y no un préstamo del castellano.

En el librito de Juan Miranda M. el signo tata es un dibujito de un viejo con bastón. Es un fenómeno muy importante, ya que ejemplifica el proceso por el cual las formas más antiguas de los signos han sido sustituidas por formas más modernas, y actualmente más fáciles de entender.

\section{6. mama}

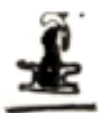

Dick Ibarra Grasso 1953:193:050,

mamaykita, "a tu madre, a tu señora".

El signo mama tiene una importancia especial. En el corpus apareció una sola vez. De la misma manera que el signo anterior, es un dibujo de una mujer en unas andas. El hecho de que se trata de una mujer se ve gracias a una ñañaqa que se encuentra encima de la cabeza, igual a la ñañaqa de la momia de la quya, la mujer del Inca en el dibujo de Don Phelipe Guaman Poma de Ayala. Precisamente la ñañaqa, las andas y la forma de un bulto me convencen de que se trata de signos creados como muy tarde en el siglo dieciséis, cuando las momias todavía viajaban en andas.

La revisión de los signos que parecen antiguos indica que pudieron originarse en siglo dieciséis. Ya he llamado la atención sobre el hecho de que los signos dibujados o pintados provienen de signos anteriores, formados de arcilla, en bases de arcilla, o formados de pedrezuelas, también en forma de espirales con base de arcilla. Los signos, fechados o no, reflejan categorías de organización de ideas típicamente andinas: dualismo, oposiciones binarias, veinticuatro horas que comienzan al atardecer.

\section{Conclusiones}

1. Las pictografías catequéticas son un grupo de escrituras similares que provienen de una tradición antigua y común. Lo indica la diferenciación regional de los signos.

2. La presencia dentro de la escritura de signos no cristianos y precristianos obliga a compararlos con la escritura mencionada por Christoual de Molina en 1575, y por el Inca Garcilaso de la Vega en 1609, y vista por Joseph de Acosta antes de 1590. Todas las menciones antiguas y todos los textos pictográficos conocidos son textos religiosos, de oraciones o de mitos, a pesar del cambio de 
religión: de una andina, que aquí para simplificar la discusión llamaré religión incaica, a la católica, apostólica y romana en su forma andina.

3. La crítica interna de los signos indica claramente que la escritura ha evolucionado y sigue evolucionando, y que el proceso de sustitución de signos antiguos por signos nuevos es un proceso permanente. Lo demuestran las formas de los numerales y de palabras tales como tata y mama.

4. Algunos rasgos de notación sugieren que originariamente la notación fue creada en una lengua diferente del quechua. No se anotan los sufijos, tan importantes para el quechua. Se cambia la última vocal o la última sílaba de un signo, un fenómeno desconocido en quechua. El no marcar los sufijos es posible en una lengua con sintaxis fija, que no es el caso ni del quechua ni del aymara. La omisión de la última vocal y el no marcar el sufijo del objeto directo pueden ser rasgos aymaras.

5. La génesis del sistema actual pudo comenzar cuando las élites andinas se cristianizaron. Simbólicamente se puede fechar el comienzo de la cristianización de la élite andina hacia el año de 1545, cuando en Cuzco se bautizó Pawllu Inqa, que intentaba crear un estado inca-cristiano bajo protección española (Lamana 2008). Su final también se puede fechar simbólicamente hacia la mitad del siglo diecisiete, cuando la Iglesia Peruana reconoció a todos los indios como cristianos, aunque malos (Marzal 1983).

6. Exige explicación el porqué la escritura catequética existe solamente en Qulla Suyu, y faltan menciones de su existencia fuera de Qulla Suyu. Las menciones sobre una escritura precolonial provienen todas o de Cuzco, o de tradiciones conectadas con Qulla Suyu (Szemiński 2009).

7. También se debe explicar la ausencia de textos coloniales. El testimonio de Joseph de Acosta de 1590 sugiere que las ruedas de pedrezuelas eran frecuentes y visibles en cualquier cementerio. Sin embargo, las escasas menciones y la limitación de la escritura a textos catequéticos, parecen confirmar las informaciones de Christoual de Molina de 1575, según las cuales el conocimiento de la escritura se limitaba a los sabios llamados amawta.

8. Dick Ibarra Grasso (1953) tiene razón: las pictografías catequéticas son una herencia de una escritura antigua andina, anterior a la conquista, utilizada por los Incas y por las élites de Qulla Suyu para anotar textos de índole religiosa.

9. La tradición de la existencia de tal escritura se conservó en la obra de Fernando de Montesinos, cuyos datos provienen probablemente de Cuzco (Szemiński 2009). 
10. Me parece muy urgente verificar mis argumentos y mis conclusiones con un estudio de las pictografías aymaras.

\section{Referencias bibliográficas}

Acosta, Joseph de

1979 [1590] Historia Natural y Moral de Las Indias en que se tratan las cosas notables del cielo/ elementos/metales/plantas y animales dellas y los ritos/y ceremonias/ leyes y gobierno de los indios, compuesto por el Padre ..., religioso de la Compañía de Jesús. Edición preparada por Edmundo O’gorman con un prólogo, tres apéndices y un índice de materias. Fondo de Cultura Económica, México.

Doctrina christiana y catecismo para instrucción de indios...

1985 [1584-85] Doctrina Christiana y Catecismo para instrucción de los Indios, $y$ de las demas personas, que han de ser enseñadas en nuetra sancta Fé. Con vn confesionario, y otras cosas necessarias para los que doctrinan, que se contienen en la pagina siguiente. Compuesto por auctoridad del Concilio Prouincial, que se celebro e la Ciudad de los Reyes, el año de 1583. Y por la misma traduzida en las dos lenguas generales, de este Reyno, Quichua, y Aymara. Impresso con licencia dela Real Audiencia, en la Ciudad de los Reyes, por Antonio Ricardo primero Impressor en estos Reynos del Piru, Año de MDLXXXIIII Años. Facsímil del texto trilingüe, Corpus Hispanorum de Pace, Volumen XXVI-2, Consejo Superior de Investigaciones Científicas, Madrid.

Durston, Alan

2007 Pastoral Quechua. The History of Christian Translation in Colonial Peru, 1550-1650. History, Languages, and Cultures of the Spanish and Portuguese Worlds. University of Notre Dame Press, Notre Dame.

Guaman Poma de Ayala, Don Phelipe

1615 Nueva Corónica y Buen Goberno

http://www2.kb.dk/elib/mss/poma/

Husson, Jean-Phelippe

2001 [Traduction, commentaire et notes de]: La Mort d' Ataw Wallpa ou La fin de l' Empire des Incas. Tragédie anonyme en langue quechua du milieu du XVIe siècle. Edition critique trilingue quechua-espagnol-français. Avant-propos de Nathan Wachtel. Patiño, Genève.

Inca Garcilaso de la Vega

1991 [1609] Comentarios Reales de los Incas. Edición e índice analítico y glosario de Carlos Aranibar. Fondo de Cultura Económica, Lima. 
Ibarra Grasso, Dick Edgar

1953 La Escritura Indígena Andina. Biblioteca Paceña, Alcaldía Municipal.

Lamana, Gonzalo

2008 Domination without Dominance: Inca-Spanish Encounters in Early Colonial Peru. Duke University Press, Durham.

Marzal, Manuel

1983 La transformación religiosa peruana. PUC Fondo Editorial, Lima.

Miranda M., P. Juan

1988 Catecismo. Diuswan Munanakuypi kawsanapaj. Sucre.

Mitchell, William P. y Barbara H. Jaye

1996 Pictographs in the Andes: The Huntington Free Library Quechua Catechism. Latin American Indian Literatures Journal 12(1):1-42.

Molina, Christoual de

1575 ? Relacion de las fabvlas $i$ ritos de los Ingas hecha por Christoual de molina cura de la perroquia de N[uestra] S[eñor]a de los Remedios de el Hospital delos Naturales de la ciudad de el Cuzco dirigida aL reuerendissimo Señor Obispo don Sebastian de el Artaum del conseJo de su Mag[esta]d. Biblioteca Nacional, número 3169, una copia sin fecha.

Sánchez C. Walter y Ramón Sanzetenea R.

2000 Rogativas Andinas. Boletín del INIAN-Museo 8, Serie Antropología boliviana. Cochabamba.

Santo Thomas, Fray Domingo de

1994 [1560] Gramatica, o Arte de la lengua general de los indios de los reynos del perú, Volumen I. Esta edición facsimilar es copia del manuscrito original R14332 custodiado por la Biblioteca Nacional de Madrid ejemplar numero 304, Madrid.

Szemiński, Jan

1992 Una qillqa - ¿inscripción incaica?”. REFLEJOS. Revista del Departamento de Estudios Españoles y Latinoamericanos. Universidad Hebrea de Jerusalén 1(1):50-54.

2005 ¿Qué significan "letras" en el libro segundo de "Nuevo Ophir" de Fernando de Montesinos? Anuario de Estudios Bolivianos, Archivísticos y Bibliográfico 11:585-598. Ediciones Archivo y Biblioteca Nacionales de Bolivia, Sucre.

2009 Un ejemplo de larga tradición histórica andina. Libro $2^{\circ}$ delas Memo[rí] as antiguas Historiales Y poLiticas del PirU redactado por Fernando de Montesinos. Iberoamericana, Madrid. 